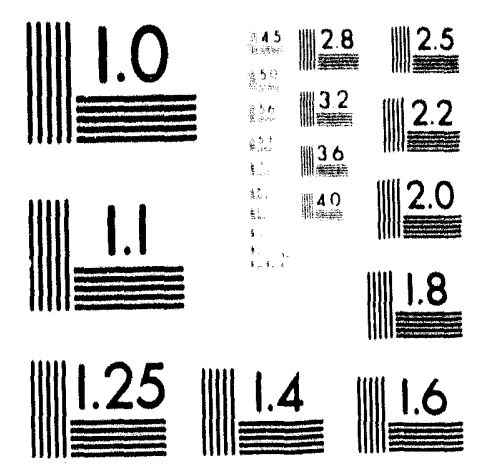



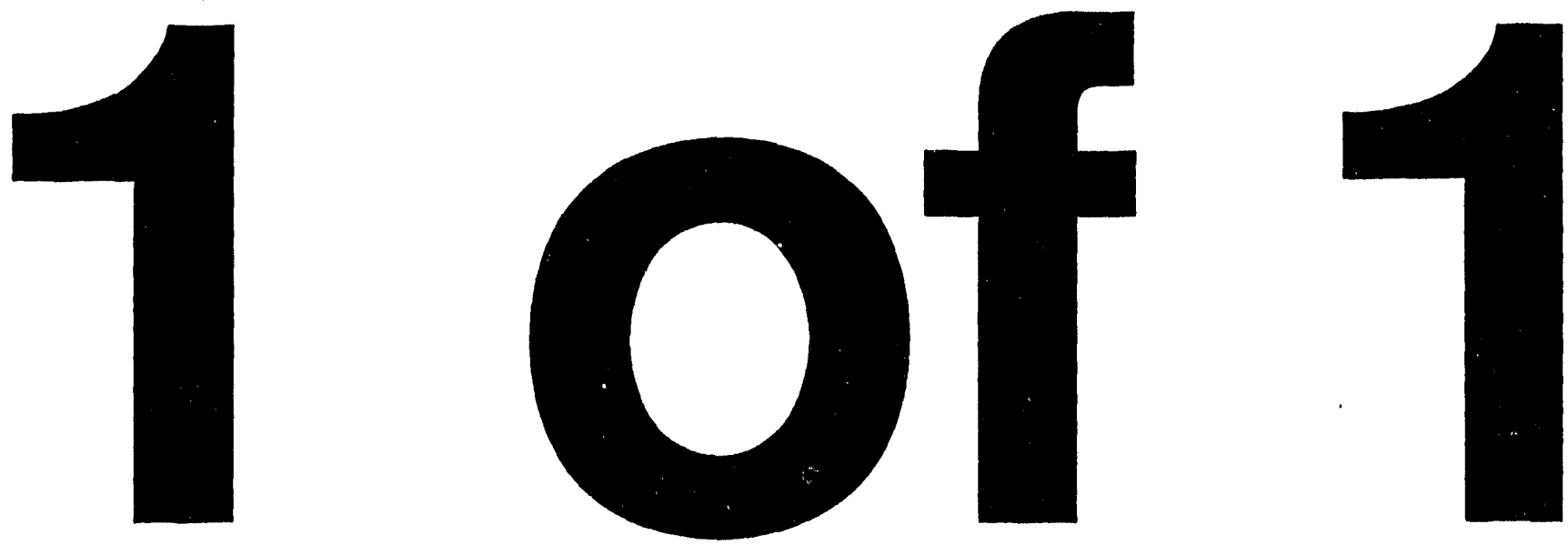


\author{
SAND92-2932 \\ Unlimited Release \\ Printed July 1993
}

\title{
FIRE HAZARDS ANALYSIS FOR THE CENTER FOR NATIONAL SECURITY AND ARMS CONTROL (CNSAC) FACILITY
}

\author{
Eric W. Klamerus \\ Components and Structures \\ Safety and Reliability Department \\ Sandia National Laboratories \\ Albuquerque, NM 87185
}

\author{
Steven B. Ross \\ Engineering Services Division \\ Science and Engineering Associates, Inc. \\ Albuquerque, NM 87110
}

\begin{abstract}
This Fire Hazards Analysis is sponsored by Plant Engineering and is prepared to support the Safety Assessment for the CNSAC Facility. This is a preliminary fire hazards analysis of a yet to be constructed facility and is based upon the current building design and the current understanding of the potential occupancy hazards. The governing occupancy for this building is personnel offices. The CNSAC facility will be dedicated primarily to two activities: (1) arms control and verification technology and (2) intelligence. This report supplements the Safety Assessment for the CNSAC facility and follows the guidance of DOE Memorandum EH-31.3 and meets the objectives of paragraph 4 of DOE Order 5480.7A, "Fire Protection". This analysis demonstrates that under "worst case" assumptions a fire in the CNSAC facility will result in consequences which are below DOE offsite guidelines for accident conditions. This report is based upon preliminary design information and any major changes to the building design may require additional analyses.
\end{abstract}




\section{TABLE OF CONTENTS}

1.0 Introduction

2.0 Description of Facility Construction

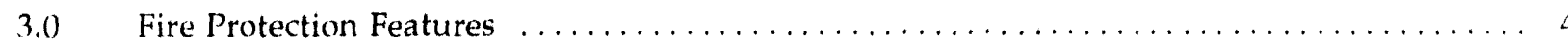

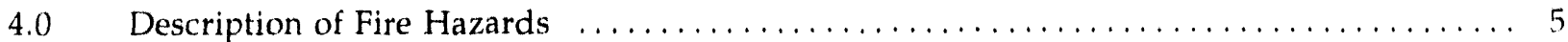

$5.0 \quad$ Protection of Essential Safety Class Systems $\ldots \ldots \ldots \ldots \ldots \ldots \ldots \ldots \ldots \ldots \ldots \ldots$

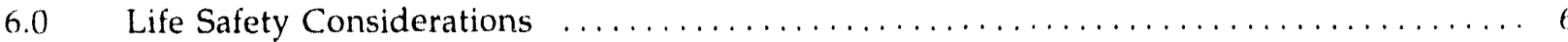

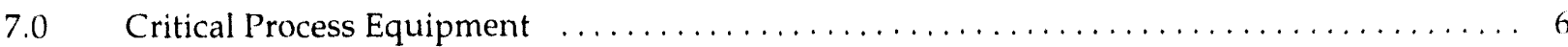

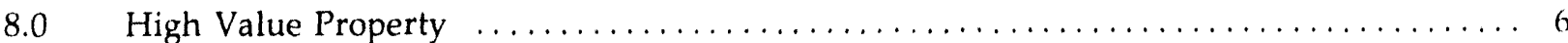

9.0 Damage Potential from the Maximum Credible and Possible Fire Loss (MCFL and

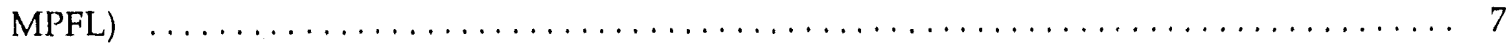

9.1 Maximum Possible Fire Loss Scenarios $\ldots \ldots \ldots \ldots \ldots \ldots \ldots \ldots \ldots \ldots \ldots$

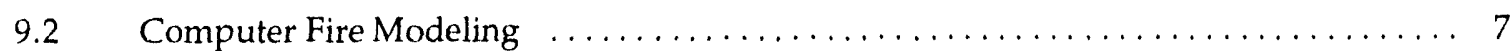

9.3 Source Term Determination $\ldots \ldots \ldots \ldots \ldots \ldots \ldots \ldots \ldots \ldots \ldots \ldots \ldots \ldots \ldots \ldots \ldots$

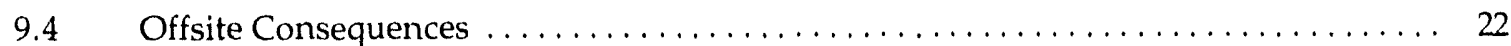

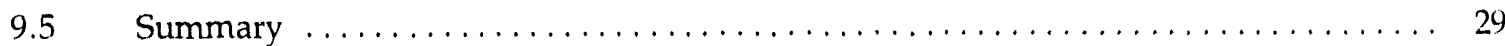

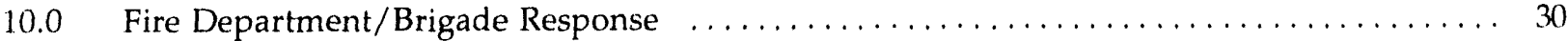

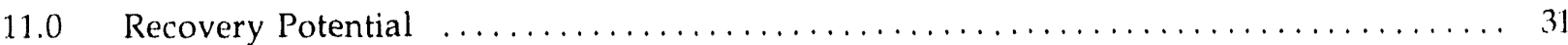

12.0 Potential for Toxic, Biological, and/or Radioactive Releases from a Fire $\ldots \ldots \ldots \ldots \ldots 31$

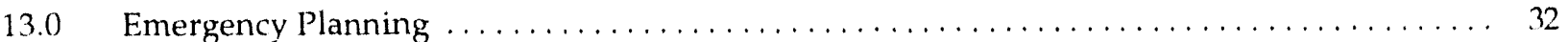


14.0 Security and Safeguards Considerations Related to Fire Protection

15.0 Natural Hazards (earthquake, flood, wind) Impact on Fire Safety

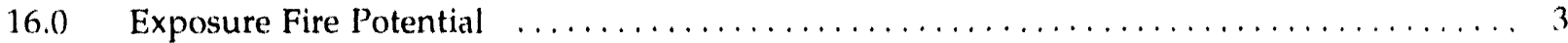

$17.0 \quad$ References $\ldots \ldots \ldots \ldots \ldots \ldots \ldots \ldots \ldots \ldots \ldots \ldots \ldots \ldots \ldots \ldots \ldots \ldots$

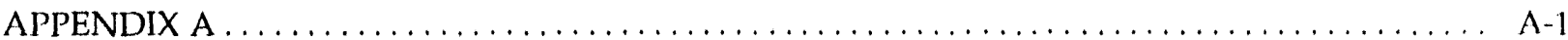

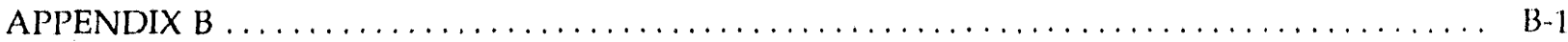


TABLE OF CONTENTS

1.0 Introduction .

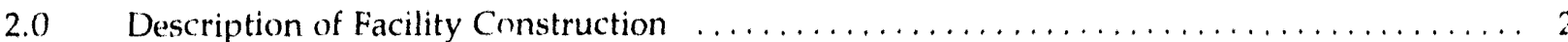

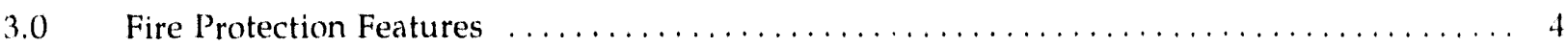

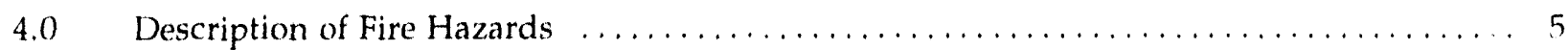

$5.0 \quad$ Protection of Essential Safety Class Systems $\ldots \ldots \ldots \ldots \ldots \ldots \ldots \ldots \ldots \ldots \ldots$

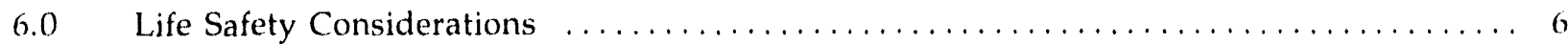

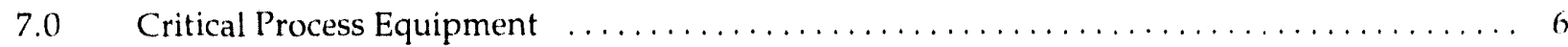

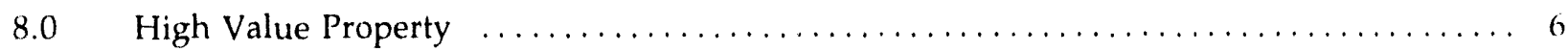

9.0 Damage Potential from the Maximum Credible and Possible Fire Loss (MCFL and

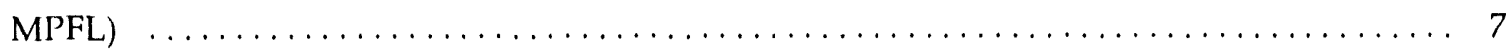

9.1 Maximum Possible Fire Loss Scenarios $\ldots \ldots \ldots \ldots \ldots \ldots \ldots \ldots \ldots \ldots \ldots$

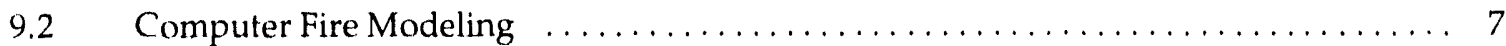

9.3 Source Term Determination $\ldots \ldots \ldots \ldots \ldots \ldots \ldots \ldots \ldots \ldots \ldots \ldots \ldots \ldots \ldots \ldots \ldots \ldots$

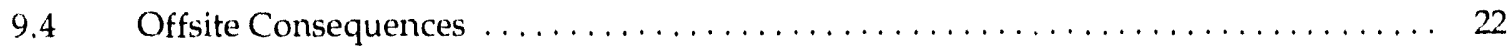

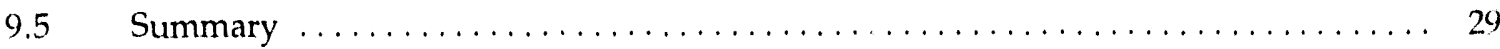

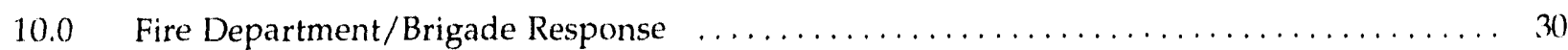

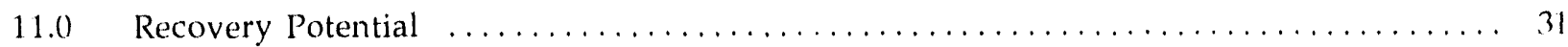

12.0 Potential for Toxic, Biological, and/or Radioactive Releases from a Fire $\ldots \ldots \ldots \ldots \ldots .31$

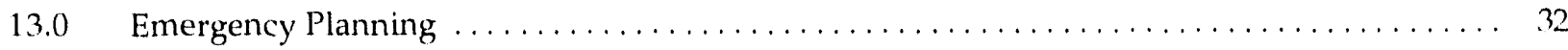


15.0 Natural Hazards (earthquake, flood, wind) Impact on Fire Safety

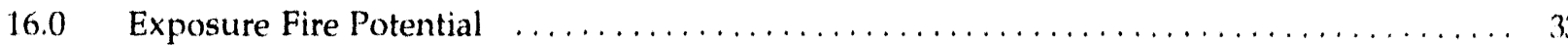

$17.0 \quad$ References $\ldots \ldots \ldots \ldots \ldots \ldots \ldots \ldots \ldots \ldots \ldots \ldots \ldots \ldots \ldots \ldots \ldots$

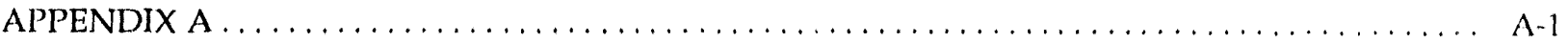

APIENDIX B $\ldots \ldots \ldots \ldots \ldots \ldots \ldots \ldots \ldots \ldots \ldots \ldots \ldots \ldots \ldots \ldots \ldots \ldots \ldots \ldots$ 


\section{LIST OF FIGURES}

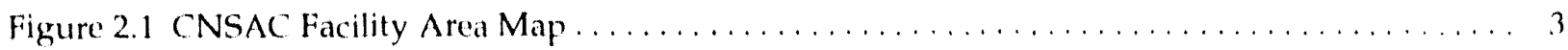

Figure 9.1 CNSAC Facility Maximum Possible Fire Loss Event Tree . . . . . . . . . . . . . . . 8

Figure 9.2 CNSAC Facility Maximum Possible Fire Loss Fault Tree $\ldots \ldots \ldots \ldots$

Figure 9.3 FIRAC Room Model for the CNSAC Facility Basement Area $\ldots \ldots \ldots \ldots$

Figure 9.4 FIRAC Hot Layer Temperature History for the CNSAC Facility Basement Area . . . . 20 
LIST OF TABLES

Table 9.1 Radionuclide Inventory

Table 9.2 Building Source Term for Selected Isotopes

Table 9.3 Consequence Calculations for the CNSAC Facility

28

Table 9.4 Centerline Dose (rem) Pu-239 (MACCS results)

29

Table 9.5 Centerline Dose(rem) Co-60 (MACCS results) 30 


\section{0) Introduction}

This fire hazards analysis for the Center for National Security and Arms Control (CNSAC) contains all the elements required by paragraph 9.a.(2)(c) of DOE Order 5.801).7A, titled "Fire Protection." These requirements are as follows:

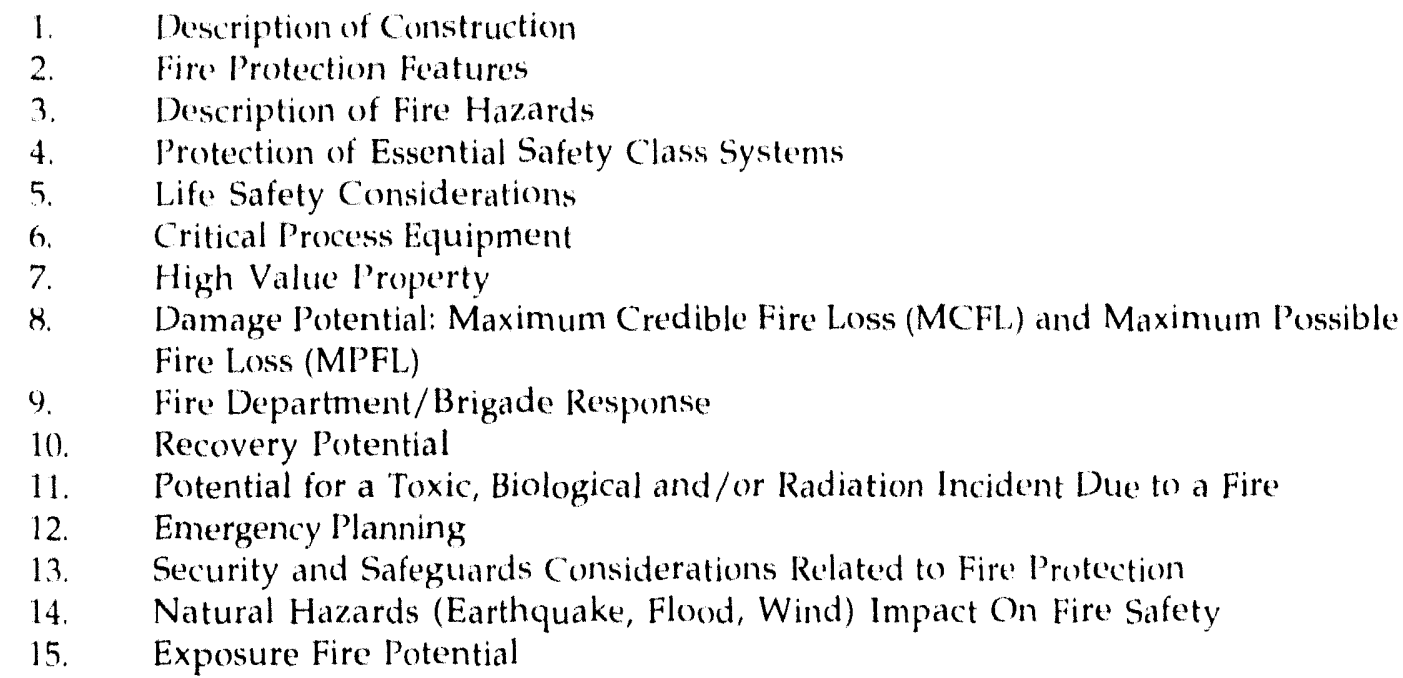

This is a preliminary fire hazards analysis of a yet to be constructed facility and is based upon the current building design as documented in Reference 1 and the current understanding of the potential hazards. The governing occupancy for this building is personnel offices. The CNSAC facility will be dedicated primarily to two activities: 1) arms control and verification technology; and 2) intelligence. Laboratories will be devoted to such activities as developing methods to monitor certain types of radiation, creating methods to monitor the production or operation of certain military weapon systems, establishing improved methods of interpreting and manipulating the data provided by monitors, and developing and fabricating mechanical, electrical, and optical devices for detection and monitoring. Machine shops will turn out parts for prototype assemblies designed in the labs, machine jigs and fixtures used in experiments, and be used in certain mechanical testing. A small photo lab vill provide a processing capability for certain classified photographic products. An unusual aspect of the facility is that approximately two thirds of it will be built to DOE Sensitive Compartmented Information Facility (SCIF)/TEMPEST requirements. A SCIF is a facility particularly constructed for handling and storing sensitive classified information and has special access control. TEMPEST is a code word for compromising emanations; e.g., the electromagnetic signals which are given off by operating equipment such as computers and which might be picked up outside the facility. Special design considerations are 


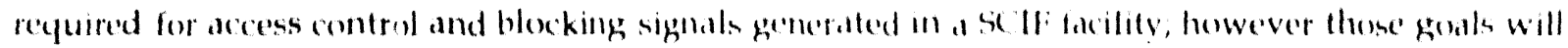
not interfere with the goal of reaching full compliance with Envirunment safety \& Health (ES\&H) regulations for the CNSAC facility. A threat assessment has been performed for the CNSAC facility using DOE/HQ guidelines and th has been determined that no special shielding of the SCIF portion of the building will be required. TEMIEST protection will be accomplished by the appropriate level of RED/BL.ACK separation of power and communication systems.

\subsection{Description of Facility Construction}

The Conter for National Security and Arms Control (CNSAC) facility will be built in Technical Area 1 at Sandia National Laboratories on Kirtland Air Force Base located in Albuquerque, New Mexico. II will be built in the area bounded by I street on the north, 9th street on the east, KAFB perimeter fencingt on the south and Sandia Buildings 805 and 807 on the west (See Figure 2.1). The area currently contains several temporary buildings and two older permanent buildings of substandard construction quality. Removal of these building will constitute the first phase of construction. The facility will house approximately four hundred people and will contain approximately 153,000 gross square feet and $86,(00)$ ne't square feet.

The CNSAC facility consists of two structures: a four-story light Laboratory/Office structure and a Lobby/Conferencing structure. The entire facility was designed to the following codes: Uniform Building Code (UBC) 1988, DOE Order 6430. : A General Design Criteria, National Fire Protection Association (NFPA) 101 Life Safety Code, as well as other applicable building codes as required by DOE Order 6430.1A.

The Laboratory/Office side of the facility is rectangular in shape and consists of four stories, and a basement. Each floor is about $28,000 \mathrm{sq}$. ft. totalling around $140,000 \mathrm{sq}$. ft. for the entire structure. Although indicated to be almost identical to Building 962 at SNL, special DOE SCIF requirements for security separation walls, interior circulations and exit requirements, additional elevator requirements, and increased requirements for seismic loads necessitated complete vertical and lateral load analysis and redesign of all columns, walls, beams and foundations.

The structural framing system of the Laboratory/Office structure consists of cast-in-place concrete beams, columns, and endwalls with precast concrete double-tee floor and roof framing systems and precast concrete window panels. A cast-in-place concrete separation wall extending from the basement 


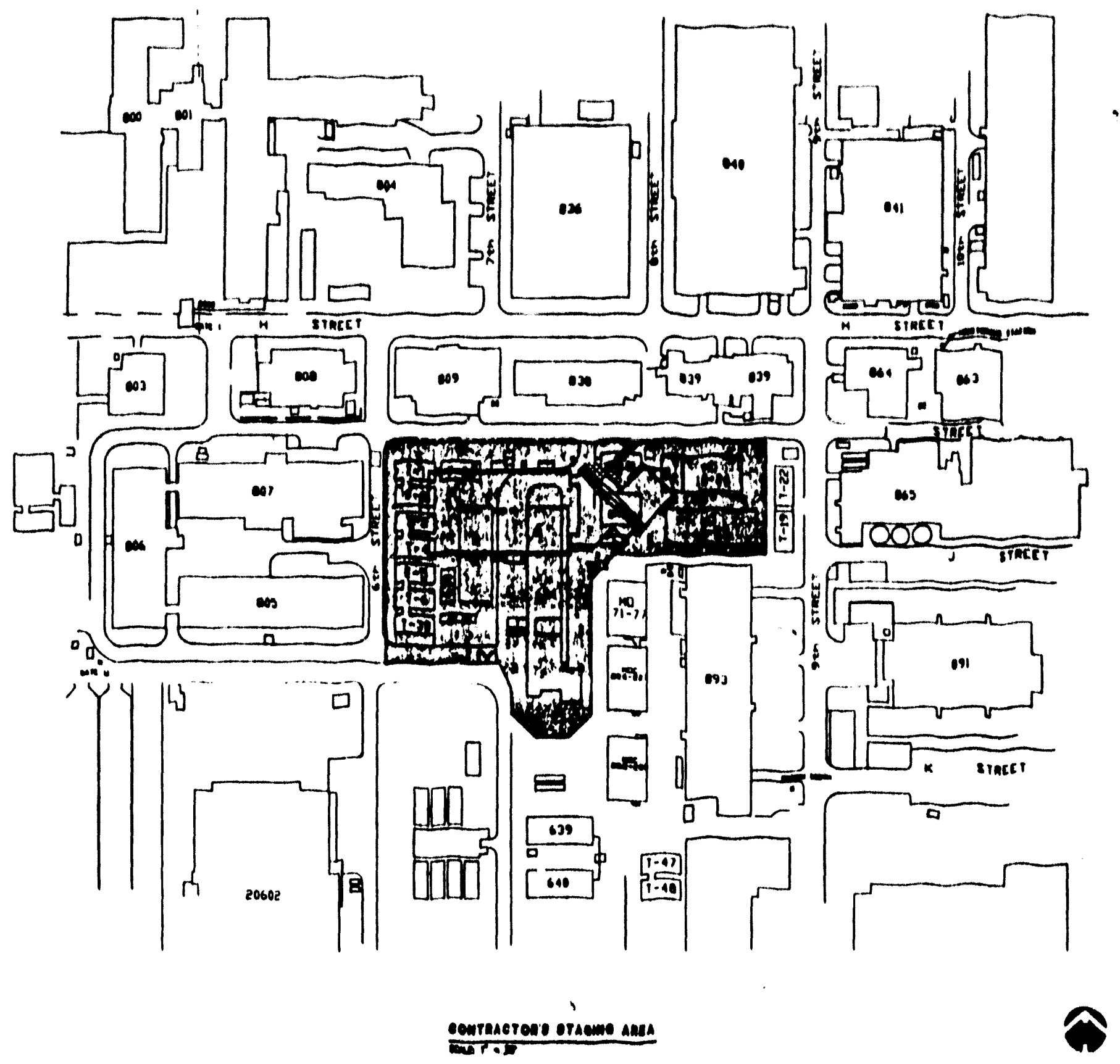

Figure 2.1 CNSAC Facility Area Map 


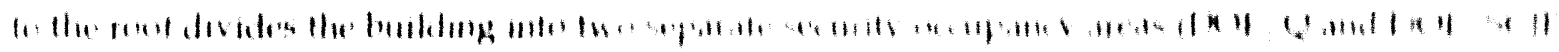

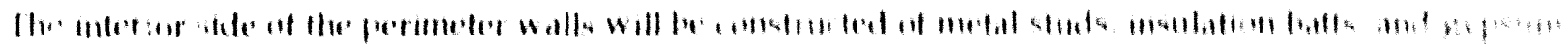

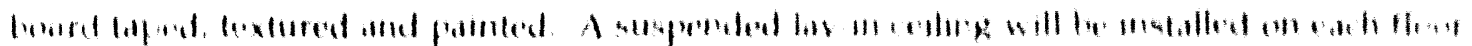

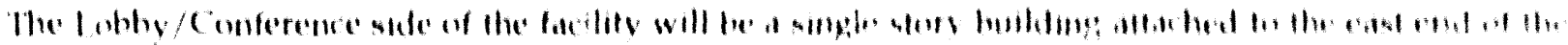

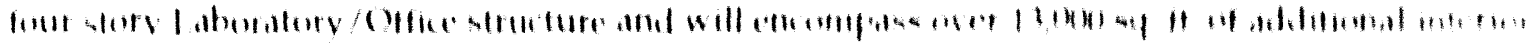

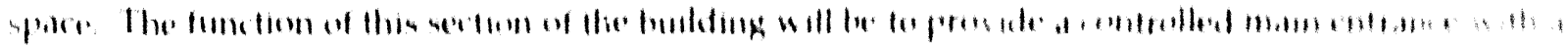
loble and anforemeng aros

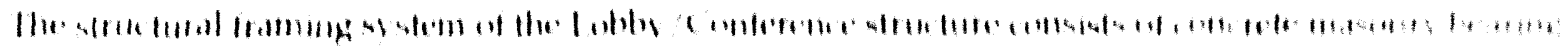

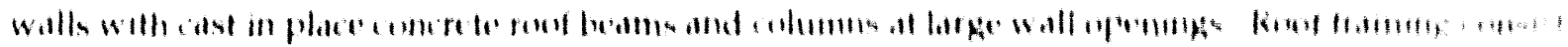

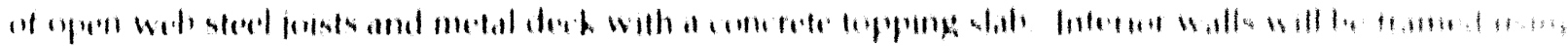

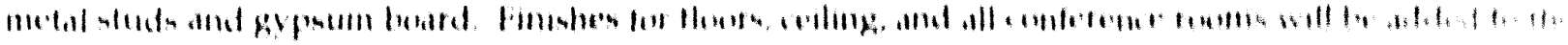

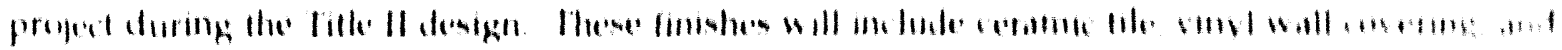
inflitis

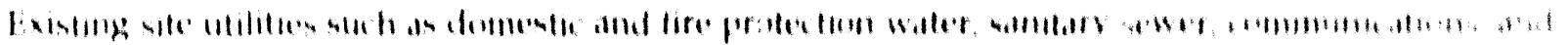

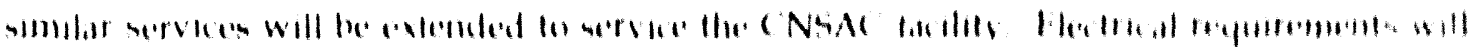

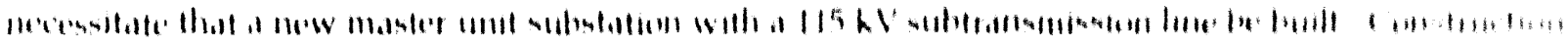

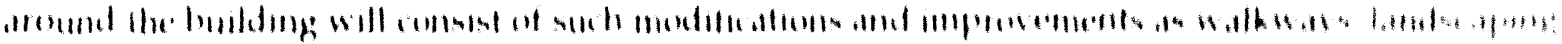

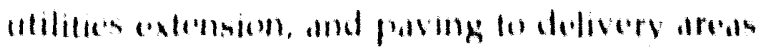

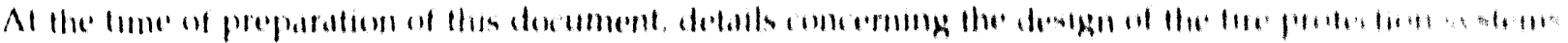

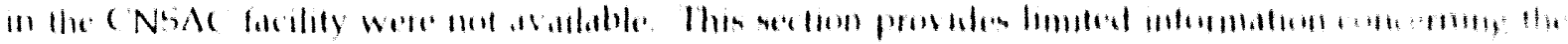

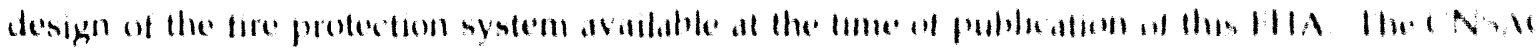

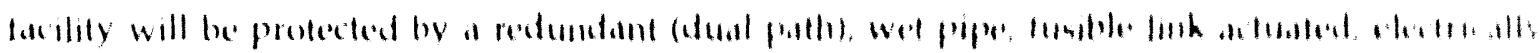

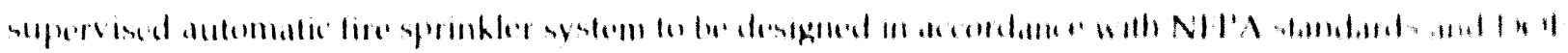

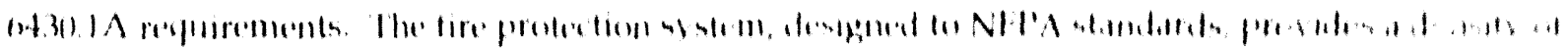

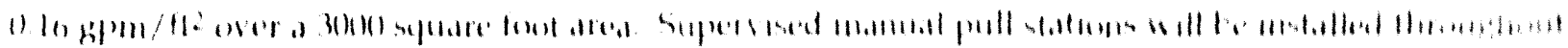

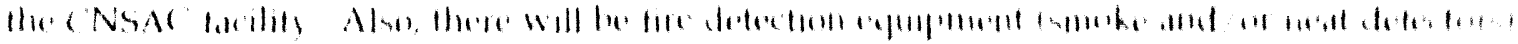

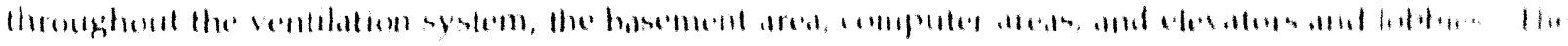

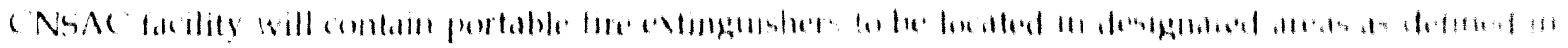




\section{NIT'A Standard HIO}

Now sumbustille loading per syuare foot in the CNSAC facility is considered to be light. The active, pastive, and operallowal fealures of the fire protection design combine to make a significant fire an unlikrly enent Automatic or mantul fire suppression should overcome the "average" fire and even a areve fite shenld be combaned in the room of origin.

\subsection{Dencription of Fire Hazards}

fimmonn hasarils (alextrical, chemical, etc., ) in the CNSAC facility are typical for any personnel nflue crupancy in most of the facility and for an industrial type machine shop for part of the bianement areat

A varily of chemicals are used in the uperation of the machine shop and the photo laboratory. These

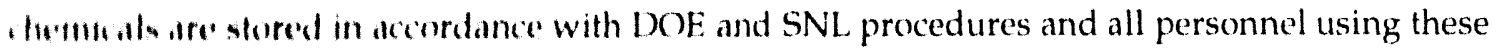
I lemili als are properly trimed. The hazardous chemicals used in these operations can be found in the

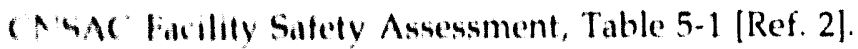

Minn in the radiondive sources to be used will be permanently stored in the facility. A storage area will lw provided in the basement of the facility for these materials. All of the radioactive sources will he alored in licked fireproof containers. Access to the materials will be limited to those trained furament whose foh functions require the use of the radioactive materials. As these sources are required Ii, laluratury use they will be moved to the appropriate laboratory in appropriate shielded containers "1. M limil the exposure to personnel at all times. Tables 5.2-1 thru 5.2-4 of Reference 2 list the Wpind radiontive sources which will be used and stored in the CNSAC facility.

Minl of the ridinactive materials that will be used in the facility are sealed sources provided by . Imumerial vendors, such as lsotope Products Laboratory and Amersham.

Hhe mijority of the. CNSAC facility does not contain any systems structures or components whose failure womld alversely affect the environment, employees, or the safety and health of the public. However, He. Humement area in the CNSAC facility will contain various amounts and types of radioactive 
materials and will require additional safety features. Although the design of the basement area has not been specified, it is assumed that the failure of the ventilation system, the sprinkler system, or the radiation monitors could potentially have an adverse affect on the environment, employees, or the safety and health of the public. Therefore these systems will be designated as safety class systems.

\subsection{Life Safety Considerations}

Basic considerations for the construction and operation of the CNSAC facility call for operational procedures which reduce the likelihood of a fire or a fire related catastrophe and facility designs will help mitigate the consequences of such an event. The CNSAC facility was designed per NFPA 101 1981, Life Safety Code classification for a new business occupancy with a hazard of contents classification of ordinary hazard. All egress components have a two hour fire rating. The exit access corridors, stairs, and vertical open space have fire dampers in all the supply air grills. Appropriate exit signage and emergency lighting is within code requirements.

\subsection{Critical Process Equipment}

For the purpose of this fire hazard analysis all systems or components that could reasonably contribute to a fire incident are subject to review and analysis. The systems which may be critical would be those associated with the use of radioactive and/or combustible material. These systems include machining tools, fume hoods and typical lab equipment. These systems will be protected by the full coverage automatic fire protection systems provided in all areas. As a result, the fire threat to or because of critical process equipment is negligible.

\subsection{High Value Property}

The overall value of the CNSAC facility is estimated to be $30-40$ million dollars. A review of facility operations indicates that there is not a particular area in the facility which contains high value property. However, there could be a significant interruption of facility operations in the event of a fire. Additionally, there will be information, classified and unclassified, stored at the facility that would be costly to replace and measures should be in place to store a backup of critical information at another facility and provide protected backups of information stored on computers. 
Maximum credible fire loss is defined by DOE Order 5480.7A, paraphrased, as that loss that might occur in a fire area if all installed fire protection systems work as designed and the value of manual fire fighting effects is omitted except for post-fire salvage and recovery. The maximum possible fire loss is, paraphrased, that loss within a fire area that could occur if both automatic and manual fire suppression efforts fail. A fire area is defined as an area bounded by a minimum of two hour rated construction. This includes doors, dampers and seals. Fire loss includes restoration costs for real and personal property less any salvage value and also includes related costs such as clean-up, production loss/interruption costs, fire extinguishment costs and consequent effects on related areas.

For the maximum credible fire scenario, it is assumed that the automatic fire suppression system is of adequate design to mitigate the consequences of the fire. It is assumed that the fire begins due to an electrical short and ignites combustibles (flammable liquids, paper products) in the area. The automatic fire protection system (FPS) then performs as designed and extinguishes the fire.

The following section presents the analysis of the maximum possible fire loss scenario. Included as part of this analysis is a discussion of the possible scenarios leading to the MPFL, computer modeling of the maximum possible fire scenario, source term determination and offsite consequence results.

\subsection{Maximum Possible Fire Loss Scenarios}

As stated above, it is assumed that for the MPFL scenario, both automatic and manual fire fighting efforts fail. The event tree in Figure 9.1 presents the sequence of "system" failures required given the occurrence of a fire in the basement area of the CNSAC facility. The specific system failures required for the maximum possible fire loss in the basement area of the CNSAC facility are presented in a fault tree in Figure 9.2. Although the fault tree has not been quantified it provides a picture of potential automatic and manual fire fighting failure scenarios which can lead to the MPFL. This fault tree covers the failure of automatic fire suppression system(s), the failure of early manual suppression by an employee in the area, and the failure of manual suppression of the fire by fire department personnel.

\subsection{Computer Fire Modeling}

As indicated in the DOE guidance on the Fire Hazard Analysis (FHA) [Ref. 3], an acceptable fire model 


\begin{tabular}{|c|c|c|c|}
\hline FIRE & $\begin{array}{c}\text { EARLY } \\
\text { MANUAL } \\
\text { SUPPRESSION }\end{array}$ & $\begin{array}{c}\text { AUTOMATIC } \\
\text { FIRE } \\
\text { SUPPRESSION }\end{array}$ & $\begin{array}{c}\text { MANUAL } \\
\text { SUPPRESSION } \\
\text { BY FIRE } \\
\text { DEPARTMENTT }\end{array}$ \\
\hline
\end{tabular}

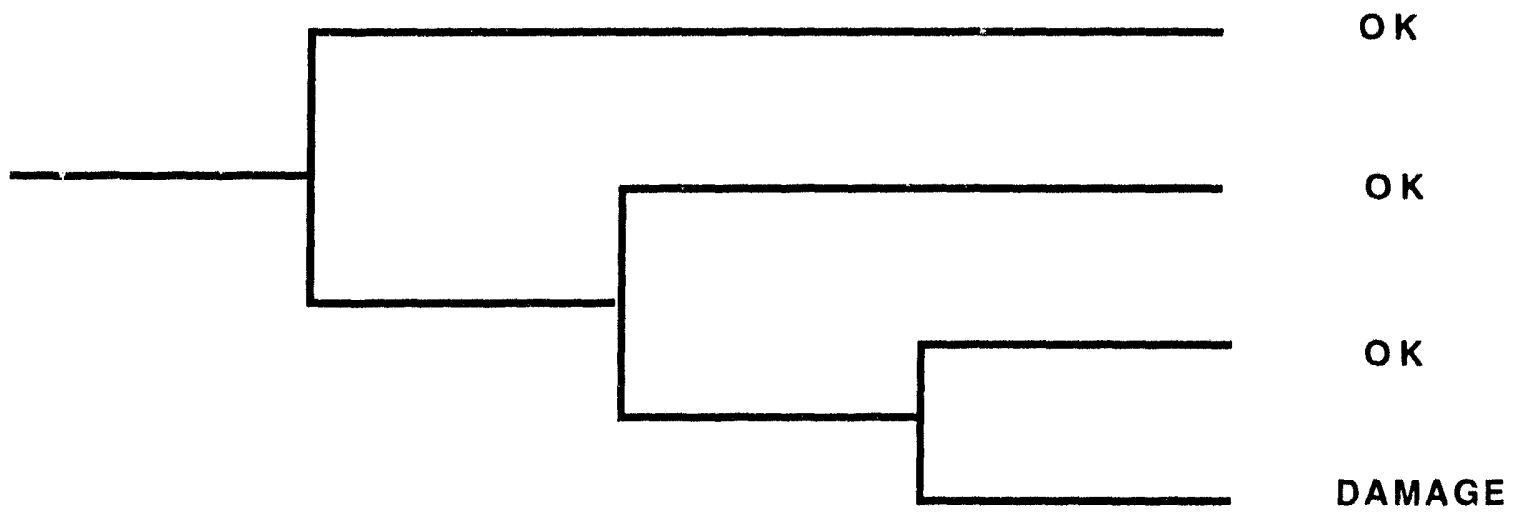

Figure 9.1 CNSAC Facility Maximum Possible Fire Loss Event Tree 


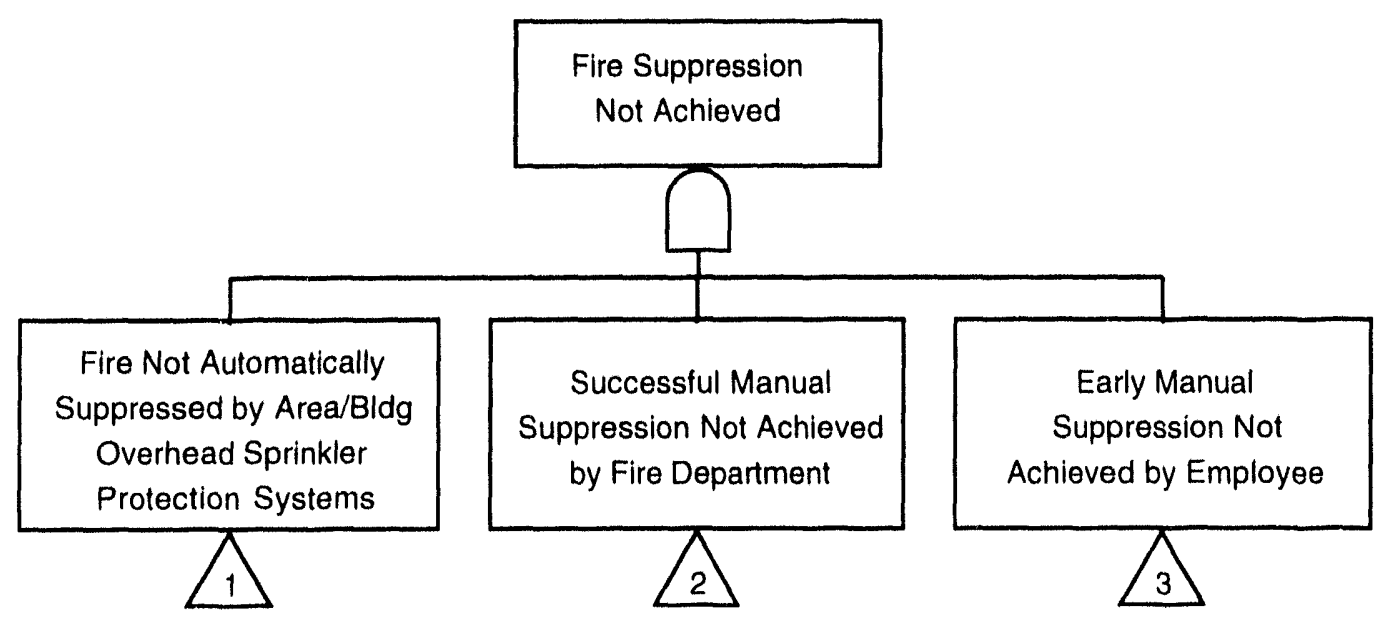

Figure 9.2 CNSAC Facility Maximum Possible Fire Loss Fault Tree 


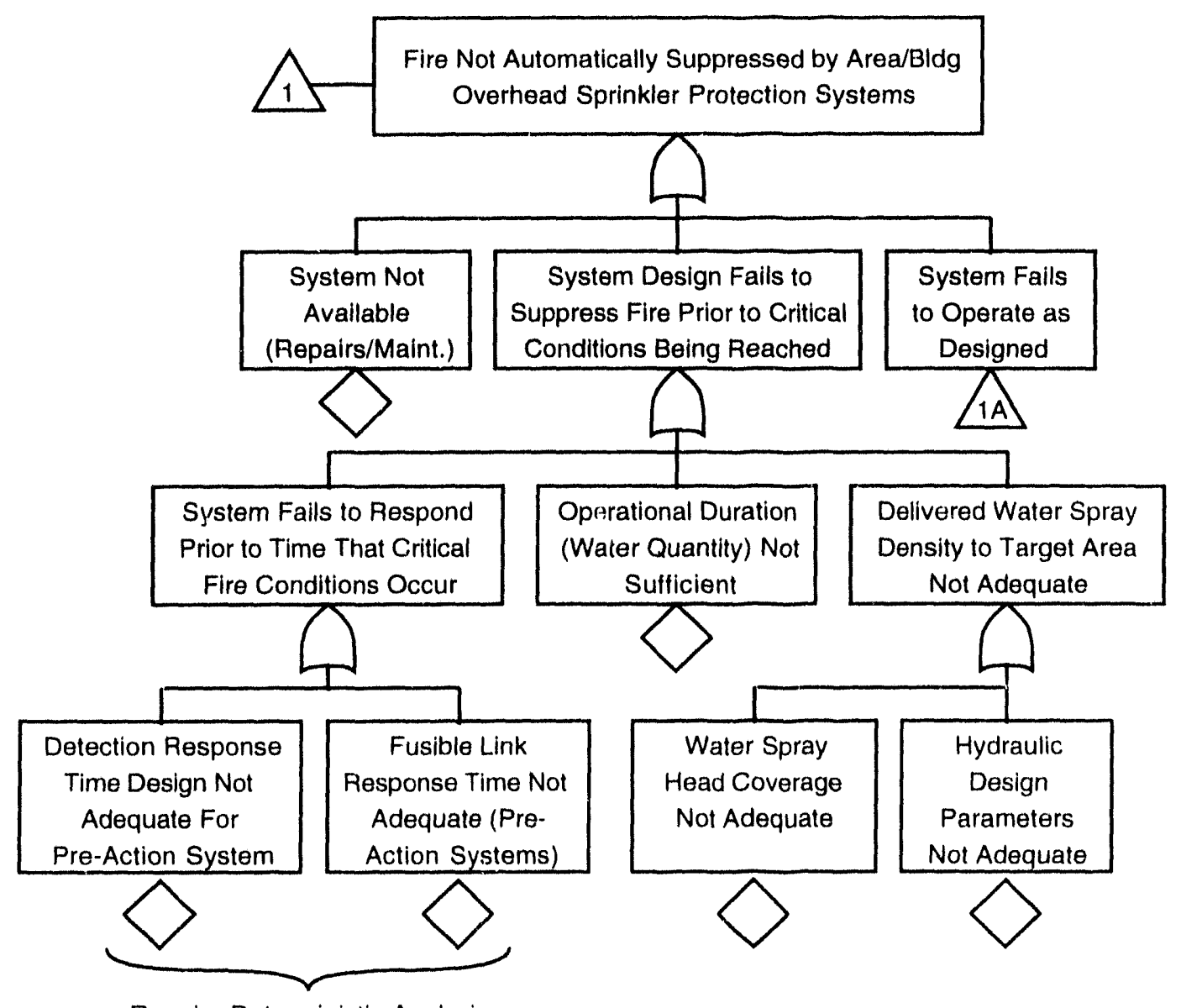

Require Deterministic Analysis

Figure 9.2 (NSAC Facility Maximum Possible lire Loss Fault Tree (cont.) 


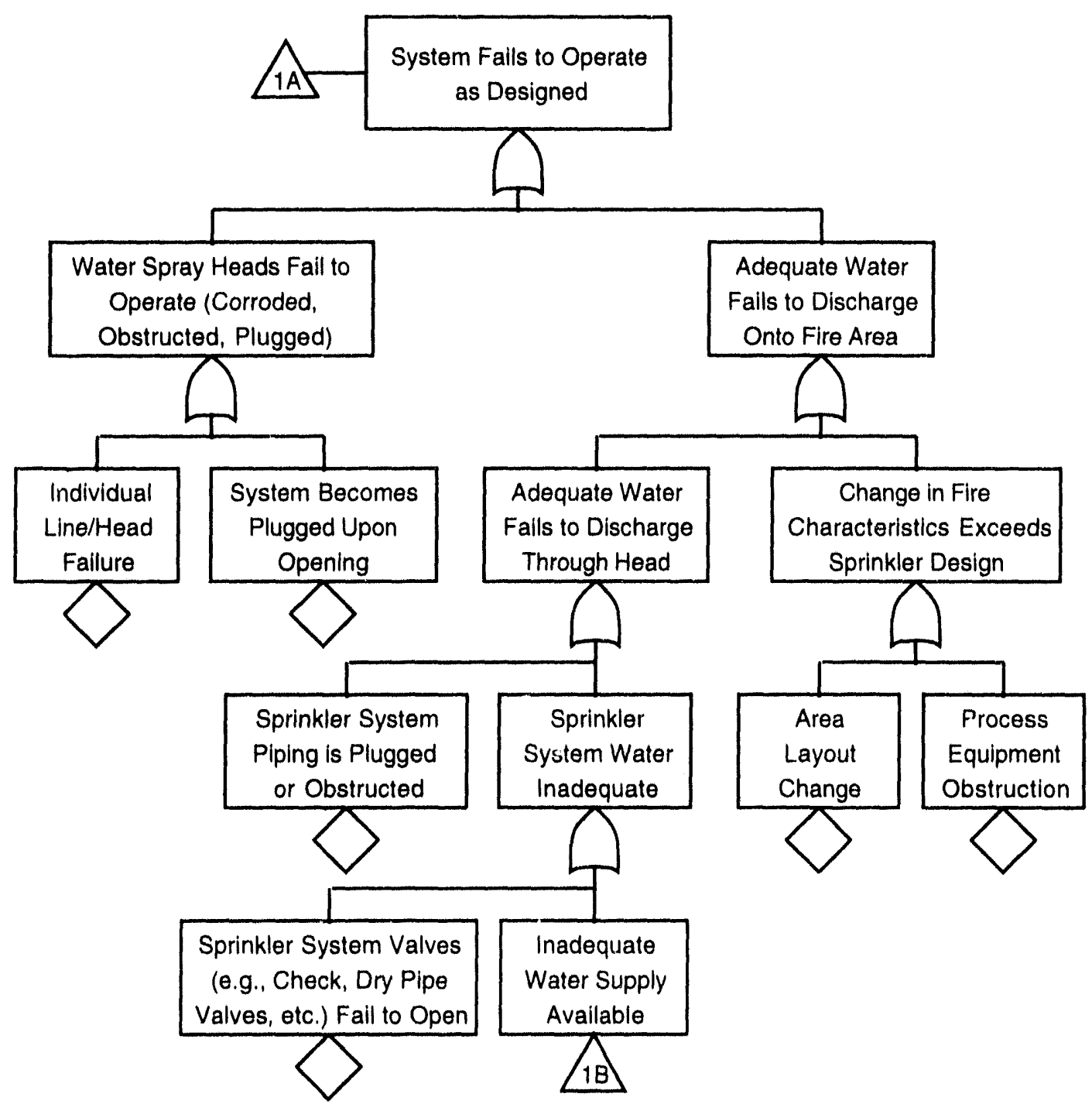

Figure 9.2 CNSAC Facility Maximum Possible Fire Loss Fault Tree (cont.) 


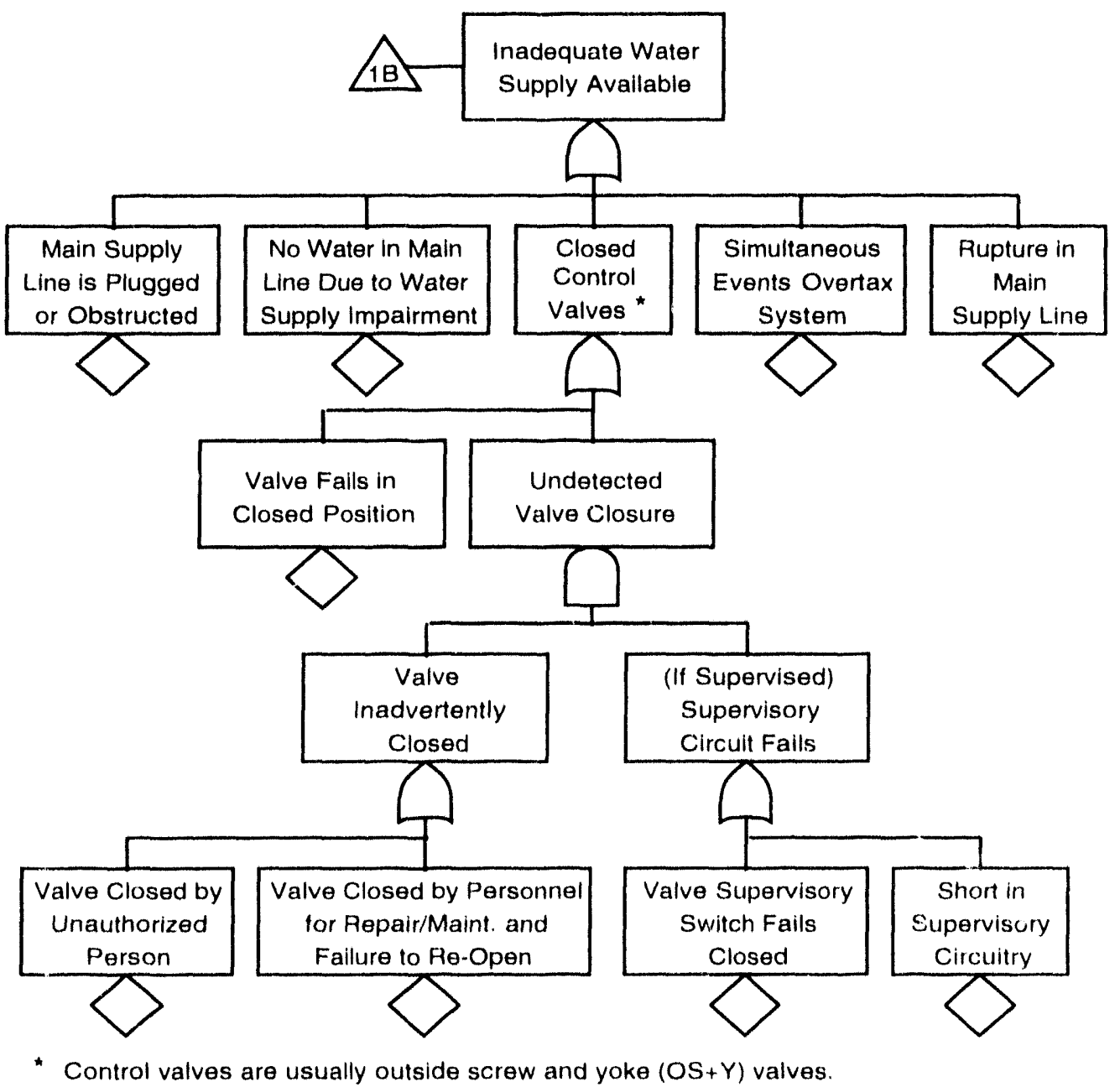

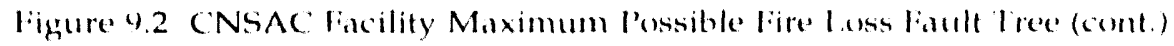




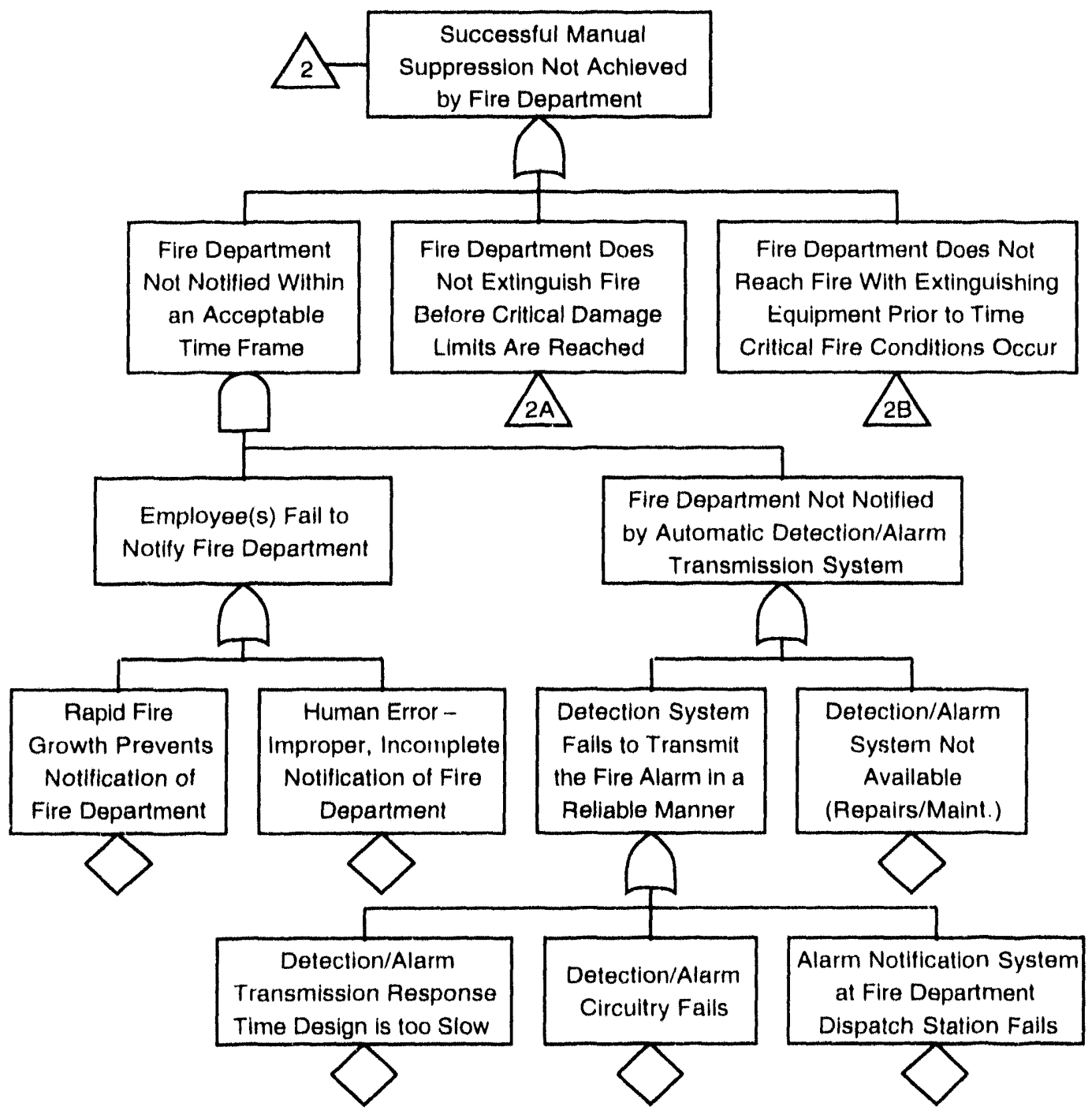

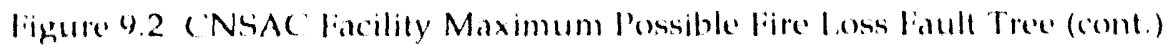




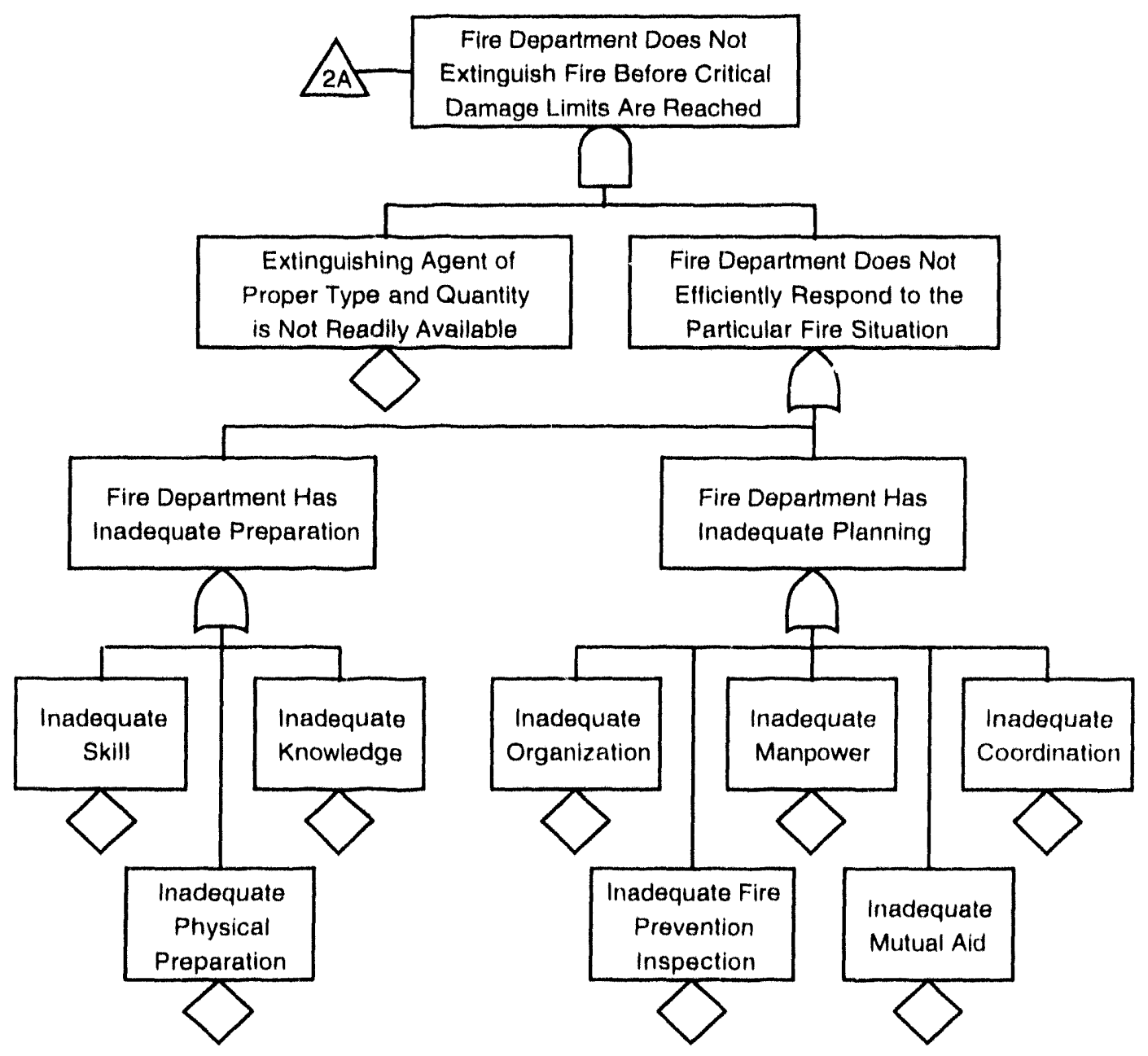

Figure 9.2 CNSAC Facility Maximum Possible Fire Loss Fault Tree (cont.) 


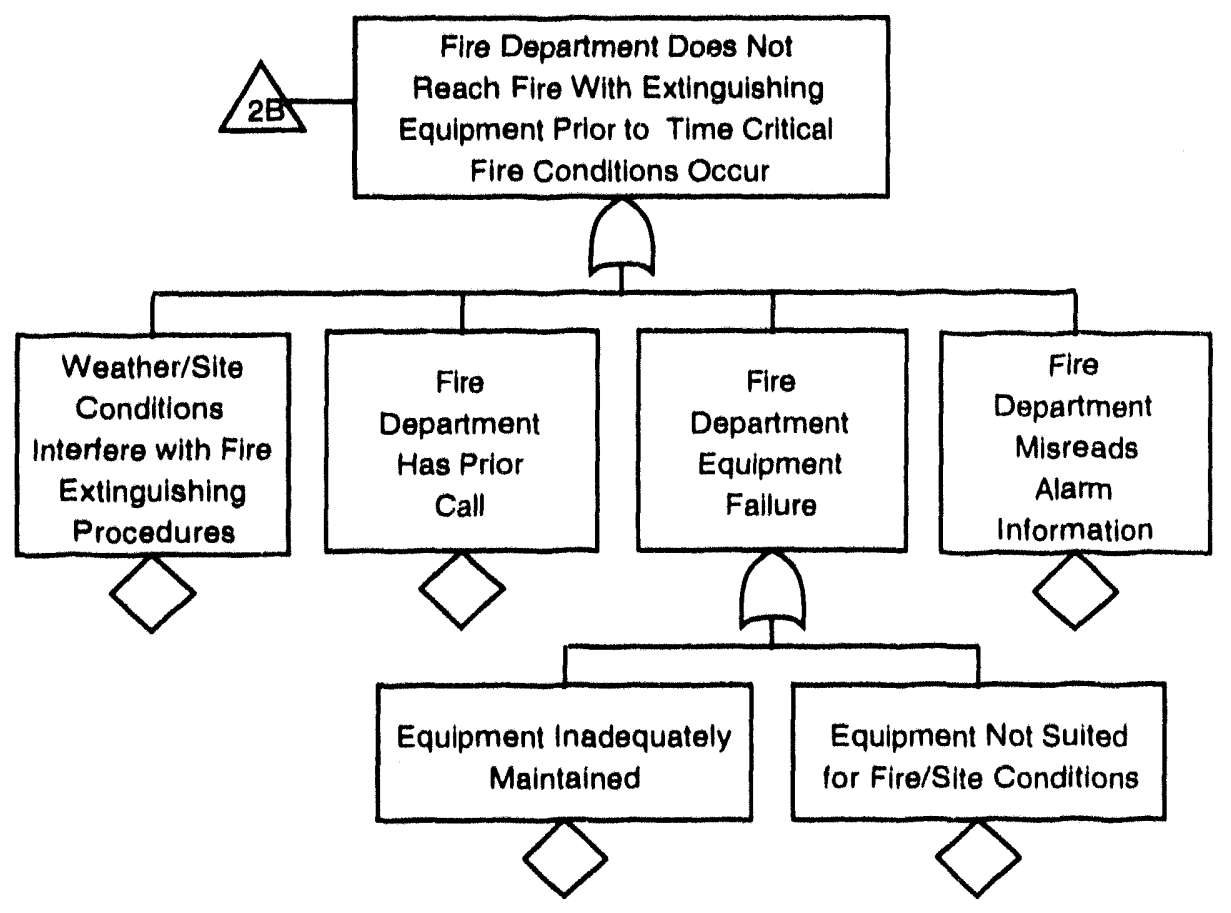

Figure 9.2 CNSAC Facility Maximum Possible Fire Loss Fault Tree (cont.) 


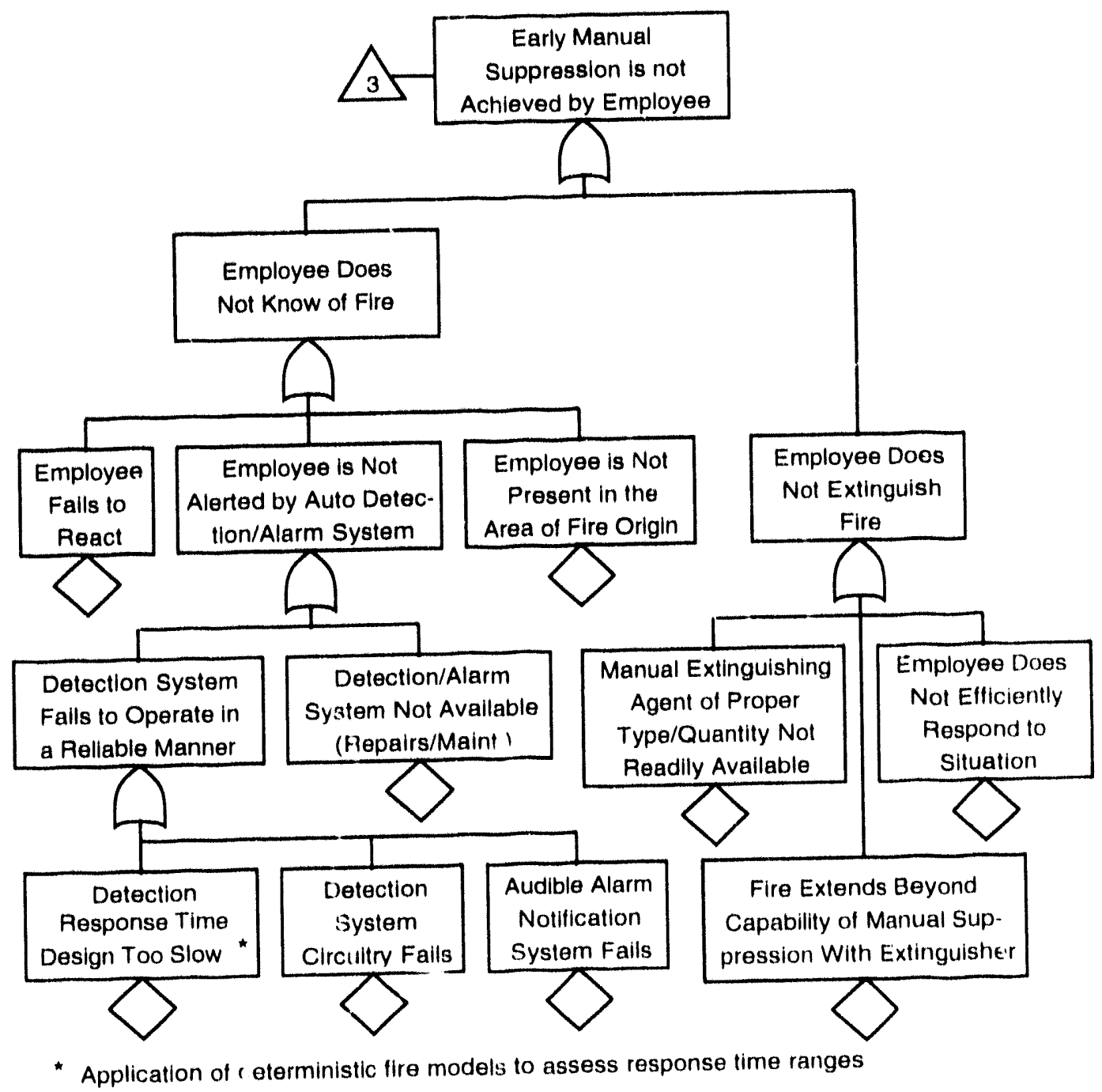

Figure 9.2 CNSAC Facility Maximum Possible Fire Loss Fault Tree (cont.) 
may be used as a tool in the development of the FHA. Such DOE guidance identified FIRAC [Ref. 4] as the model being considered for acceptance by DOE for this purpose. As such, the FIRAC computer code will be used to model the maximum possible fire scenario. The assumptions utilized in the input for FIRAC are outlined below:

- Combustibles are involved near the location where the initiating event (IE) occurs, staff or operators fail to suppress the fire, Fire Department and the automatic sprinkler system fail to suppress the fire such that the fire spreads to include the entire fire zone (or large part thereof) and radioactive material is assumed to be involved.

- Since little or no information on the actual configuration of safety, support, and process systems is known at this phase (shell design), a simple fire room model will be used to model a generic fire area within the office/lab area of the basement. The basement is chosen as the worst case due to the storage of radioactive materials in this area. This fire area will be assumed to have a length of 40 feet, a width of 40 feet, and a height of 13 feet. All the walls, ceilings, and floors will be assumed to be one foot thick concrete.

- Also, since no information is available on the ventilation rate, including exhaust rate, it will be assumed based upon guidance from Reference 5 that 5 to 6 air exchanges per hour will be typical of this fire area or about $2,000 \mathrm{ft}^{3} / \mathrm{m} 1 \mathrm{n}$. No fans or hlowers will be modeled, since no information on these are available at this time. The room pressure will be assumed to be about -0.55 in $\mathrm{wg}$.

- As part of the simple fire modeling, the fire room with two ducts (inlet and outlet), and two boundaries (inlet and outlet) will be modeled as shown in Figure 9.3. The outlet and inlet elevations will be assumed to be at ceiling level (i.e., 13 feet) as shown in the Title II architectural drawings.

- In the FIRIN Module [Ref. 4] of the FIRAC computer code, the fire will be modeled until combustibles in the room are exhausted (approximately for one hour). No radioactive materials will be assumed in this FIRAC/FIRIN analysis, since the release rates and release fraction for radioactive materials available in the code do not represent in any way the form of the radioactive material assumed to be present within the CNSAC facility (i.e., sealed or metal matrix (non-pyrophoric sources)). 


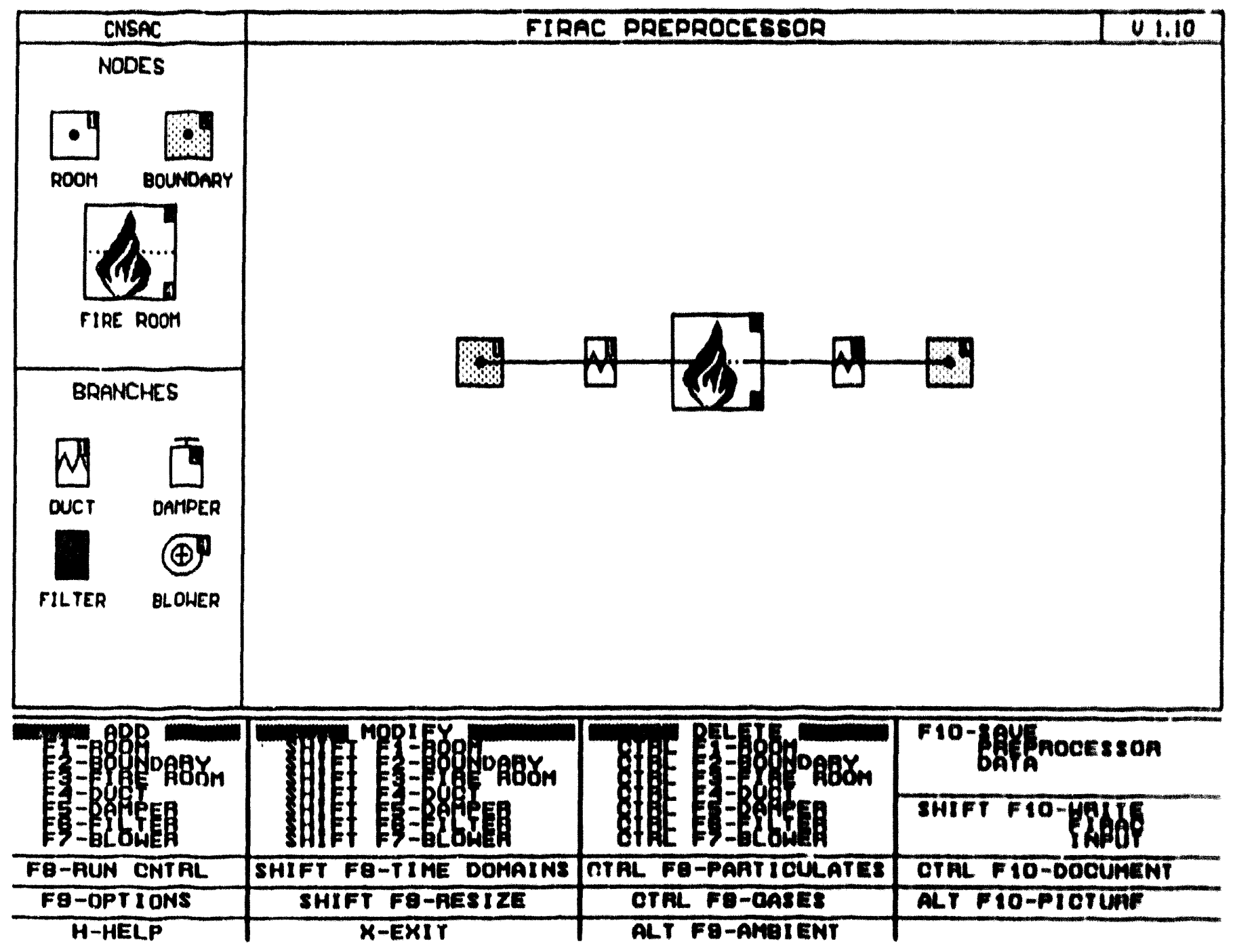

Figure 9.3 CNSAC Facility FIRAC Model 
The release of radioactive materials that could potentially be involved in the maximum possible fire scenario will be addressed in the following section.

An ignition energy model will be used instead of the burning order method. This ivill autumatically assign initially burning materials to a burning order of one, while materials at risk are assigned a burning order of two. Based upon walkdowns of other Sandia facilities and engineering judgement, it was assumed that initially $20.0 \mathrm{lbs}$ of paper material, and 4.0 pounds of solvent will be involved in the fire (combustible material near the area in which the initiating event occurs); and that $150.0 \mathrm{lbs}$ of wood, 4.) lbs of plastic, 250,0 lbs of paper, and an additional 5.75 lbs of solvent material will be at risk in the vicinity of the area where the initiating event is postulated to occur.

Figure 4.4 presents the fire compartment thermal hot layer temperature results for this analysis. From Ihim ligure, one can see that in the first 10-15 minutes the temperature is still low enough for the primible suppression or control of the fire by the local staff, the amount of smoke generated and the lical temperature (i.e., up to about $105^{\circ} \mathrm{F}$ ) in these first 10-15 minutes will be sufficient to set-off any imoke and local heat detectors in the immediate area. From the time the fire department is assumed to how up (i.e. about 10 minutes after the fire initiates) to the time the sprinkler systems are assumed to be atwated (i.e., 30 minutes) the temperature could be as high as $230^{\circ} \mathrm{F}$ (assuming no cooling).

It $\mathrm{im}$ important to notice that FIRAC does not model the action of the coolins; of the fire by either the fire department or the sprinkler system mitigating actions. As such, the temperatures shown in Figure 4.4 are the maximum temperatures attained by the MCF, given the assumed fire loading in the fire irra. In one hour, even without the mitigating action of the fire department and the sprinkler system, the fire temperature drops rapidly to about $110^{\circ} \mathrm{F}$, assuming that no further combustibles are at risk as assumed by the event tree within the fire area.

Appendix $A$ of this FHA, contains a copy of the FIRAC/FIRIN input file, along with a graphical summıry of some of the results of the analysis, i.e., fire compartment thermal fire history effects like hot laver temperature, combustible mass burn rate, volumetric flow balance; and smoke source term vs. fime ncumulation.

It in assumed that, prior to the fire occurring, the bulk of the radioactive material stored and handled III Ihe office/lab (basement) area is securely isolated from the fire by proper storage in their respective 
Fire Compartment Thermal Effects

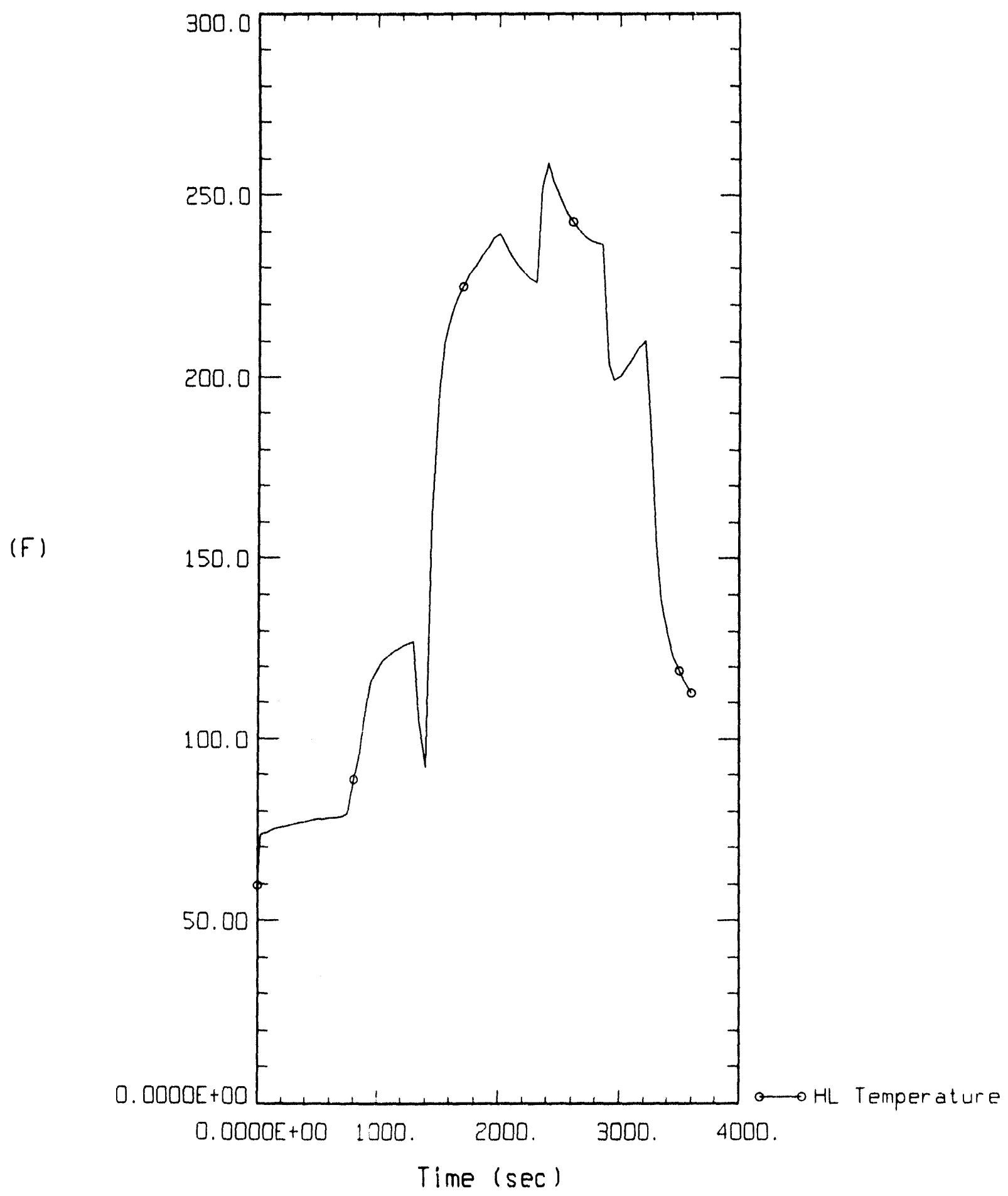

Figure 9.4 Fire Compartment Thermal History 
fire rated vaults or cabinets. However, it is very likely that a few sources that may be out of their storage location(s) may be at risk or involved in the fire. In order to bound all the consequences from all credible fire scenarios, it will be conservatively assumed that one source representing each of the radiation types (gamma, neutrons, miscellaneous sources, and alpha/fissile material) will be involved in the fire. Table 9.1 presents the radionuclide sources and inventories (in Curies) selected to represent each of the source types. For consistency, the same sources modeled in the CNSAC Facility Safety Assessment [Ref. 2] were used for this analysis.

\section{Table 9.1 Radionuclide Inventory}

\section{Source Type}

Gamma source

Neutron source

Alpha/fissile source

Miscellaneous source

\section{Radioisotope}

Co-60

Cf-252

Pu-239

U-238
Inventory - Curies (g)

$3.8 \mathrm{E}-2(3.4 \mathrm{E}-5)$

$75.0(0.14)$

$24.5(400)$

$0.0033(10,000)$

\subsection{Sourse Term Determination}

This section identifies the radioactive inventories that are at risk or material-at-risk (MAR), and the initial and building source terms that are expected to be released from the maximum possible fire (MPF) accident scenario. It is expected that the consequences to the public will be dominated by the airborne radioactive material released as a result of the fire.

The bounding consequences to the public can be calculated based on the initial source term (IST) and the building source term (BST). The amount of airborne radioactive material released to the area (IST) where the accident is postulated to occur is dependent on the airborne release fraction (ARF) of the material involved, which itself depends on the energy source produced by the accident (i.e., fire) and the radionuclide involved. In order to determine the IST, the ARF and respirable fraction (RF) must be determined for each source and then multiplied by the quantity of material. Several experiments have been conducted on release fractions from fires, specifically involving Plutonium, Uranium, or corresponding surrogate materials, and the results of such experiments are well documented throughout the literature. Most of these release fractions have been summarized for the NRC and for DOE [Ref. 6 and 7 , respectivelyl. These reports summarize the methodologies that are deemed acceptable by both 
NRC and DOE in evaluating various accident scenarios in fuel cycle or similar facilities. However, this data is limited primarily to the burning release rates from metals consisting of Plutonium and Uranium.

NUREG-1320 [Ref. 6] gives a conservative airborne release rate for Plutonium of $8.9 \mathrm{E}-6 \%$ per second. For the maximum possible fire loss, this would result in a total ARF of 3.2E-4. It was also shown [Refs. 7 and 8] that in 60 minutes, complete oxidation of $455.5 \mathrm{~g}$ (close to the limit for the CNSAC facility) of $\mathrm{Pu}$ led to a total ARF of $3.9 \mathrm{E}-6$ (which is substantially less than the assumed ARF), with a RF of 0.5 . Therefore, for conservative purposes, the $\mathrm{ARF}$ of $3.2 \mathrm{E}-04$ will be used for Plutonium metal along with a RF of 0.5 .

However, because this source is a sealed source encapsulated in Aluminum or stainless steel, complete oxidation during a one hour fire is not expected to occur. It is therefore assumed that only $10 \%$ of the sealed source will oxidize, thereby reducing the ARF by one order of magnitude.

Uranium, unlike Plutonium, is non-pyrophoric and is therefore difficult to ignite. Experiments have shown that Uranium has an upper bound ARF of $8 \mathrm{E}-6$ and $R F$ of $1.0 \mid$ Ref. 7|. Also, since the Uranium stored in the CNSAC is not limited to sealed sources, there will be no further reduction of the $A R F$. Since little data is available on the ARFs of Californium or Cobalt sealed sources, the ARF and RF for Uranium will be used for conservative purposes.

Building source terms (BSTs) and ISTs are assumed to be the same because presently there are no plans to put HEPA filters in the CNSAC facility, and no decay or deposition of these airborne materials is assumed to occur within the building. Based on these assumptions the (ISTs) or (BSTs) can be computed for each of the radionuclides assumed to be exposed to the fire and these are summarized in Table 9.2.

\subsection{Offsite Consequences}

The of fsite consequences from a release of radionuclides from the CNSAC facility due to the pustulated maximum credible fire scenario is expected to be dominated predominantly by the inhalation and immersion pathways. That is, given the dry conditions and low amounts of food stuff grown in the local area (i.e. within 10 miles from the site), other exposiure pathways (e.g., ingestion) are expected to have an insignificant contribution to the overall consequences from such postulated roleases. The offsite consequences from accident releases will be calculated by hand, instead of using a standard 
Table 9.2 Building Source Term for Selected Isotopes

Radionuclide

Co-60

Cf-252

Pu-2.39

U-2.38

\section{Inventory - Curies (g)}

$3.8 \mathrm{E}-2(3.4 \mathrm{E}-5)$

$75.0(0.14)$

24.5 (400)

$0.0033(10,000)$
IST or BST - Curies (g)

$3.0 \mathrm{E}-7(2.7 \mathrm{E}-10)$

$6.0 \mathrm{E}-4(1.1 \mathrm{E}-6)$

$3.9 \mathrm{E}-4(6.4 \mathrm{E}-3)$

$2.6 \mathrm{E}-8(8.0 \mathrm{E}-2)$

code like MACCS [Ref, 9] since presently, MACCS is unable to model half of the radionuclides listed in Table 6.3-2 of the CNSAC Facility Safety Assessment [Ref. 2]. However, MACCS will be used to benchmark the consequence hand calculations for the Plutonium and Cobalt releases, since these are the only radioisotopes modeled included in the MACCS database and the dose or exposure from Plutonium is expected to dominate.

The following equation is used to calculate the 50-year committed effective dose equivalent (CEDE) from the inhalation of radionuclides released to the environment (committed dose to other organs are calculated in similar way).

$$
C E D E_{\text {inhalation }}=B S T * S A * \chi / Q * B R * D C F_{\text {inhalation }}
$$

Where

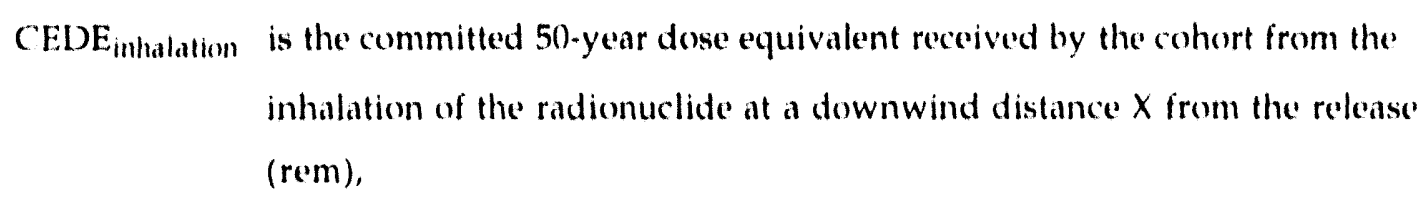

BST

is the building source term or amount of airborne material released to the environment in curies or grams (Table 9.2)

$\chi / Q \quad$ is the dispersion factor in sec $/ \mathrm{m}^{3}$ (See Equation 3.2-1 of the CNSAC Facility Safety Assessment (Ref. 2])

$B R$ is the breathing rate $\left(3.3 \times 1()-4 \mathrm{~m}^{3} / \mathrm{sec}\right)$ |Ref. 2 | 
DCFinhalation is the committed effective - dose conversion factor from inhalation for a given radionuclide (rem/Ci) [Ref. 10]

SA

is the Specific activity, converts grams to curies (Ci). Notice that, if $Q$ is given in $\mathrm{Ci}$ already, $\mathrm{SA}$ is equal to 1.

The following equation is used to calculate the committed effective dose equivalent (CEDE) from immersion in the plume containing the radionuclides released to the environment (dose to other organs are calculated in a similar way).

$$
\mathrm{CEDE}_{\mathrm{jmm} \operatorname{msion}}=\mathrm{BST} * \mathrm{~S} \Lambda * \chi / \mathrm{Q} * \mathrm{DCF} \text { immersion }
$$

Where

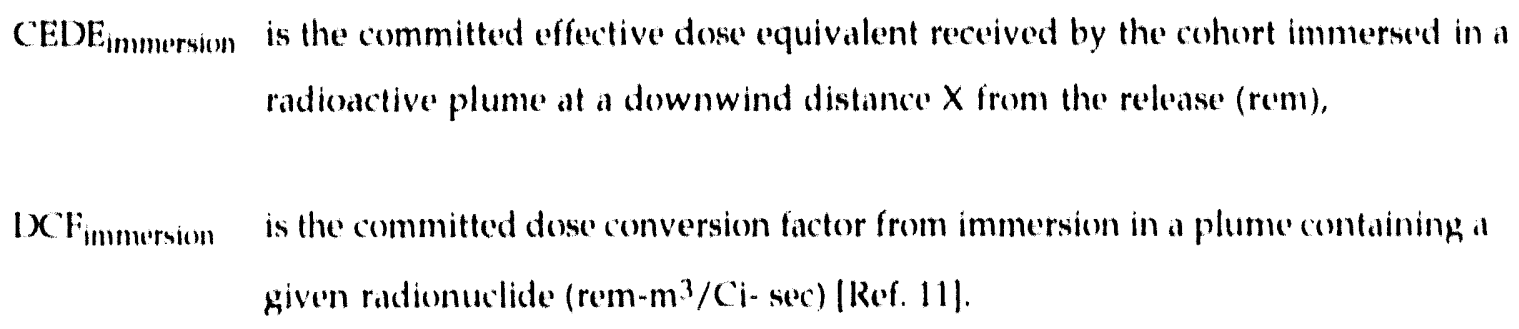

The overall committed effective dose equivalent (CEDE) received by the receptor (i.e., onsite. ar offsile) from airborne radioactive sources is calculated by adding the doses received from the two exposure pathways (i.e., inhalation and immersion). In other words, the total commitled atfective dose equivalent recoived is given by:

$$
\text { CEDE } \text { Tuthl }=\mathrm{CEDE}_{\text {inholution }}+\mathrm{CEDE} \text { immersiom }
$$

Besides the above mentioned equations, the following assumptions will be used to determine the offsite consequences from the maximum credible fire scenario:

The BST in Curies for each of the radionuclides representing each of the radiation types is taken from Tible 9.2. 
- $\quad$ All respirable material will be assumed to have one particle size (i.e., $1 \mu \mathrm{m}$ AMAD).

- No ingrowth and decay will be assumed for all the radionuclides released to the environment (i.e., BST).

- All exposure or concentration calculations will be made assuming a l'asquill stability class F, with no rain conditions and one meter per second wind speed.

- A breathing rate of $3.4 \times 10-4 \mathrm{~m}^{3} / \mathrm{sec}$ (heavy activity) will be assumed for conservative purposes.

- Release occurs at ground level. Under realistic conditions, during a fire scenario the release will tend to be elevated due to the buoyancy of the plume due to the heat generated, also due to the fact that the area in which the maximum credible fire scenario is postulated to occur (i.e., office/lab area of the basement) is exhausted through a dedicated exhaust system which will vent to the top of the CNSAC facility, about 20 meters in height).

- A release duration of one hour is assumed.

- Exposure calculations will be carried out to a distance of $1 \mathrm{Km}(50), 1(1), f(1), 6(6)(), 9(0)$ and 1000 meters), since exposures beyond that distance are expected to be below the deminimus level.

- Building wake effects will be assumed (for conservallism purposes) anly at short distances (i.e., clok) moters) since building wake effects will predomilnote alt short distances. For distances greater or equal fo flo meters slandard Ciatussian plume modtels will be used (sece equation .3.2-1 |R(t. 2|), and no credil will be token for building wake effects (conservative approach). The following equation will be used fo defermine the volume created by the wake cavity |Rof. 2|:

Volume wake cavily $=H \cdot W \cdot X_{\text {waits }}$ 
Where

$H$ and $W \quad$ are the building height and width, respectively

$X_{\text {cavity }}$ is the wake cavily length, and it is calculated from the

following cyuation depending on the ratio between the building length $(L)$ and its height $(\mathrm{H})$, i.e., L/H:

For short buildings $(\mathrm{L} . / \mathrm{H} \leq 2.0)$

$X_{\text {avily }} / H=L / H+A(W / H) /|1.0+B(W / H)|$

Where

$$
\begin{aligned}
& A=-2.11+3.7(1 / 11) \cdot 1 / 1 \\
& B=-11.15+0.3(15(1 . / H)-1 / 1
\end{aligned}
$$

I al concentration within the wake cavity will be calculated by dividing the amount of airborne materinl to the environment (BST) by the wake cavily volume calculaled with the above aguations. The height of the (NSAC lacility is abuet $20 \mathrm{~m}$ (65.7 11 ), ith width ahout $18.9 \mathrm{~m}$ (6.2 f), and its length about $37.2 \mathrm{~m}$ (122 f1). Using these dalla and the above cepuations, the volume of the wake coveity is colculated to be about $20,720 \mathrm{~m}$ ' $(7.31,649.6(1))$

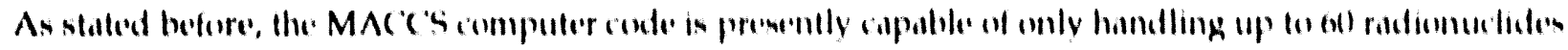

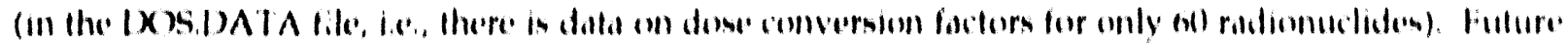

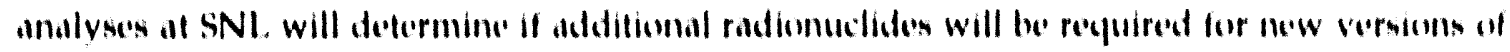

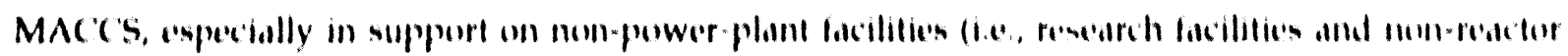

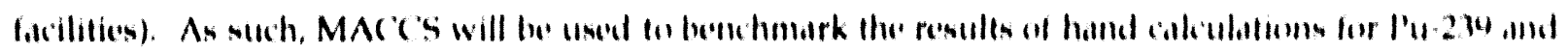

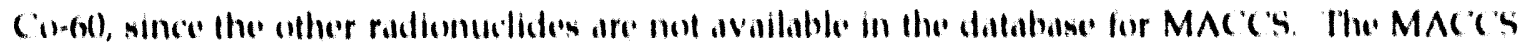
computer cokde wis run under the following ansumpticuss and inpult

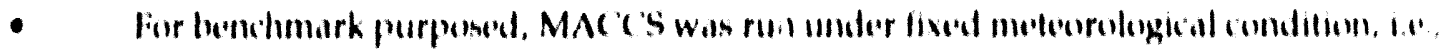

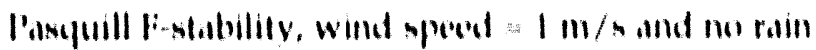

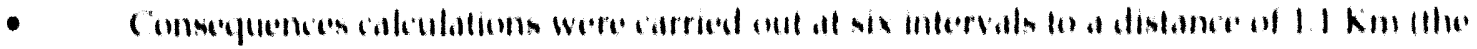

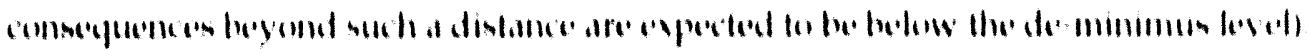


- No relocation or evacuation of exposed individuals was considered. This assumes exposure to the total amount of material release for the duration of the accident. That is, mitigating actions (i.e., evacuation, sheltering, decontamination, interdiction, relocation, etc.) were ignored in the public consequence calculations, since the main objective is to determine the doses at the plant boundary, and at different lecations around the facility.

- Potential economic impacts due to contamination and mitigating actions were ignored in this analysis.

- Both a release duration and plume duration of one hour wis assumed.

- MACCS was configured to calculate the doses and health effects to the same organs evaluated by the hand calculations, le... effective whole budy dose cipuivalent (EDE), lungs, bone marrow, and bone surface.

- Public health risks were only ovaluated for total cancere latent fittalities; carly

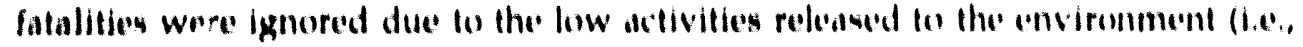
BST).

Table 9.3 summarizes the results of the dose hand calculitions for ench of the modioncuclides in table 8.2 for both the inhilation and immersion pathways, and for the three different organs, using the cefuations presented in this section and the appropriate dose conversten factors.

As shown in Table 4.3, the tollal effective dose equivalent from all polthways and from all the

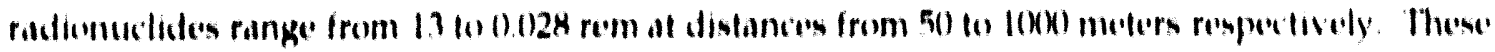

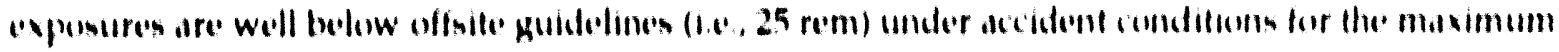

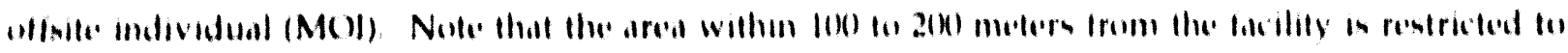

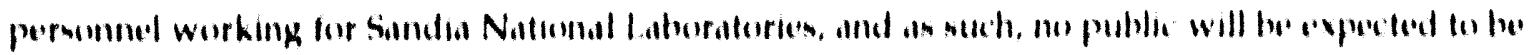
lewalled al sherler dislancess 
588888

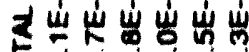
5 o

5888 웅

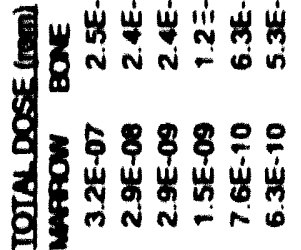

858888 崖岕出出 3 N

$88 ㅇ ㅡ=$ 四岁出岁出出 e $-n-n$

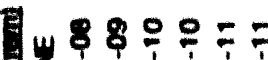
8 岁岁岁崖 gon-N-n. $8880==$ 由. 岩岩岩岩岩

$088==$ 出出岩崖它

5 88888 日出出出出出 n n n n . -

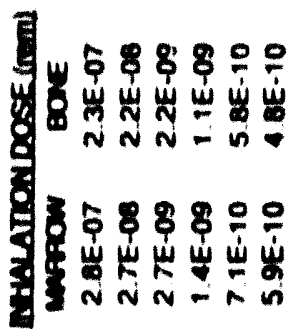

658888 3 岕岕出出岁

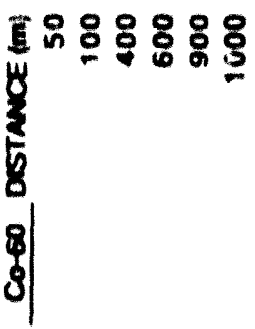

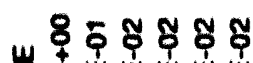
目出出出出出 ヘNA穴

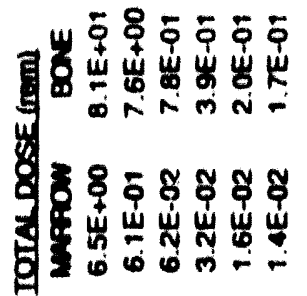

\section{두웋ㅎㅎㅇㅇㅇ 岁出出出出 N N $N-\infty$ 的}

$O=N \cong N$

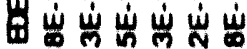

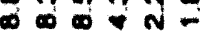

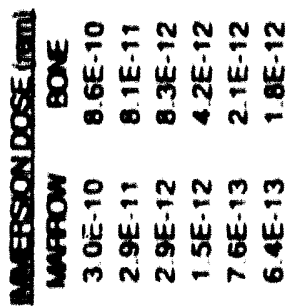

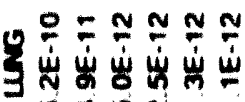
nonn - -

858 웅 옹 㟒出出岁出 TNAMN.

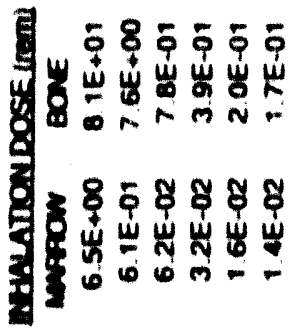

бㄷㅎㅇ

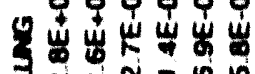
$\exists \stackrel{N}{N}=0$ N

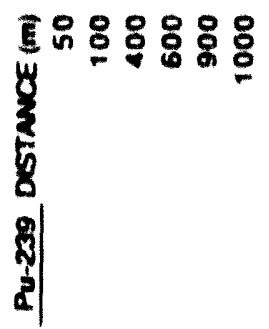

ํำำ ㅇำ

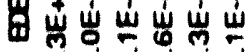

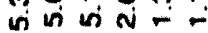

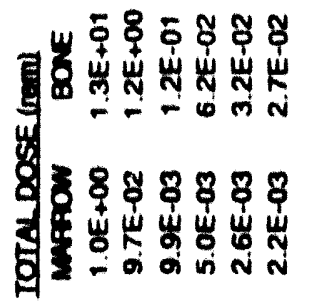

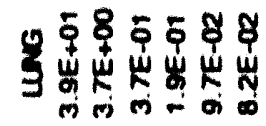

$80=N \simeq$

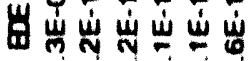
- - 6 in

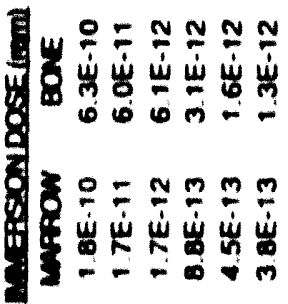

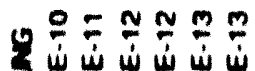

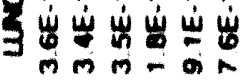

85888 崖岩出出

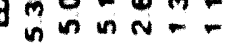

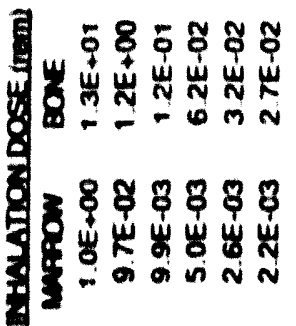

58 508 焉点出出出岕

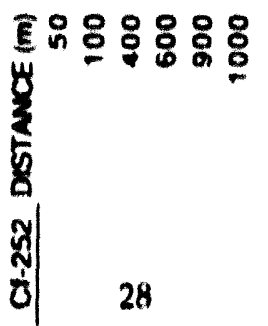

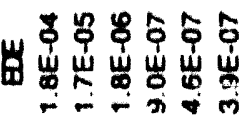

두웅ํㅇㅇํㅇ

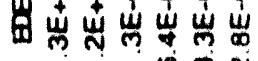
- -

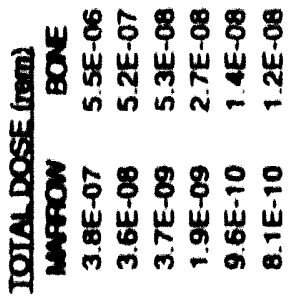

후웋ㅎㅎㅎㅎ 目岕出岕出崖 ai 岁

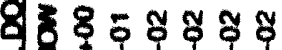
군

0838888

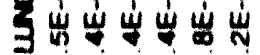

0 후웋ㅎㅎㅎㅎㅎㅜ 当岩崖岕出 $0000 .$.

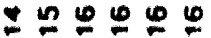

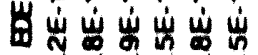
त 100 in

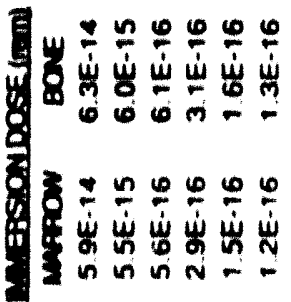

영 웅오은

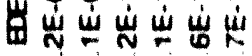
N N N - n

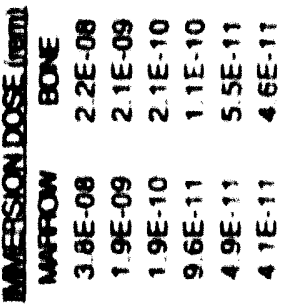

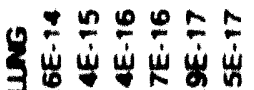
$0882==$ 3 岁出案岩嵌 N- - o n o

옹ㅎㅇㅇㅇㅇ 希崖岩岩岁

ธำ $5 \% 8$

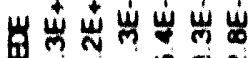

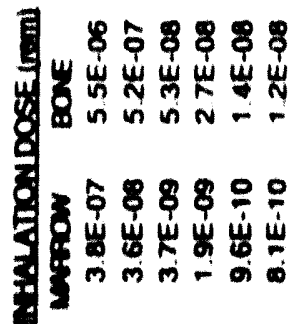

838888

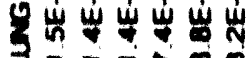

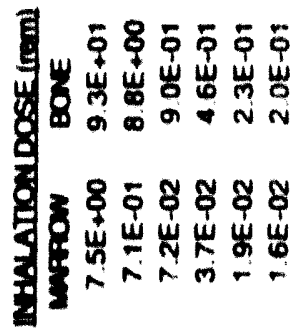

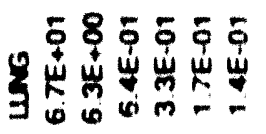

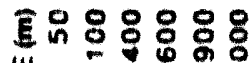<smiles>C=CC=CC=C</smiles> 
Also, as predicted, the exposure to $\mathrm{Pu}-239$ exceeds those of other radionuclides. C1-252 gives a dose which is over $30 \%$ lower than that from Pu-239. Exposure from the rest of the radionuclides (i.e., Co-60 and (1-238) are orders of magnitude smaller than those from Pu-239. The total dose from the exposure to Pu-239 (EDE in rem) ranges from 7.8 to 0.016 rem for distances from 50 to 1000 meters, respectively.

As stated before for benchmark purposes, the MACCS computer code was run to determine the exposure from the release of $\mathrm{Pu}-239$ under constant meteorological conditions. The results from MACCS are close to those calculated by hand. Table 9.4 summarizes the results from MACCS for a release of 245 Curies of Pu-239 and Table 9.5 summarizes the results from the exposure to $3.8 \mathrm{E}-2$ Curies of $\mathrm{Co}-6 \mathrm{6} \%$.

As one can see from Table 9.4 and Table 9.5, the doses from MACCS are within the range of those calculated by hand. Notice that MACCS results are given for a given range and not a single location. Appendix B contains the complete results of the MACCS runs (i.e, CNSAC.OUT files).

\subsection{Summaxy}

Although it is very unlikely to expect that the automatic FPSs will not function as designed or that manual fire fighting efforts would not be effective, even under these "worst case" assumptions the consequences will be below DOE offsite guidelines for accident conditions.

Table 9.4 Centerline Dose (rem)

Pu-239 (MACCS results)

\begin{tabular}{|c|c|c|c|c|}
\hline Distance (m) & EDE & Lunus & Marrow & Bune \\
\hline 0.100 & $2.1 E+()$ & $8.2 \mathrm{E}+1)$ & $1.7 \mathrm{E}+11$ & $2.1 \mathrm{E}+1$ \\
\hline $100(1-200$ & $2.7 \mathrm{E} \cdot 1$ & $1.0 \mathrm{E}+1)$ & $2.1 \mathrm{E}-1$ & $2.6 \mathrm{E}+0$ \\
\hline $20(1)-4(10)$ & $8.0 \mathrm{E}-2$ & $3.1 \mathrm{E}-1$ & 6. $3 \mathrm{E}-2$ & $7.4 \mathrm{E}-1$ \\
\hline $4(10)-600$ & $3.11:-2$ & $1.2 \mathrm{E}-1$ & $2.4 \mathrm{E}-2$ & $3,0 \mathrm{E}-1$ \\
\hline $6(1)-4())$ & $1,4 \mathrm{E}-2$ & $5.5 \mathrm{E}-2$ & $1.1 \mathrm{E}-2$ & $1.4 \mathrm{E}-1$ \\
\hline 9001.1100 & 8.0E-3 & $3.1 \mathrm{E} \cdot 2$ & $6.4 E-3$ & $7.9 \mathrm{E}-2$ \\
\hline
\end{tabular}


Takle 9.5 Centerline Dose(rem)

Co.60 (MACCS results)

$\begin{array}{lcccc}\text { Distance (m) } & \text { EDE } & \text { Lunos } & \text { Marrow } & \text { Bone } \\ 0-100 & 1.3 \mathrm{E}-6 & 6.9 \mathrm{E}-6 & 4.2 \mathrm{E}-7 & 3.5 \mathrm{E}-7 \\ 100-200 & 1.6 \mathrm{E}-7 & 8.7 \mathrm{E}-7 & 5.3 \mathrm{E}-8 & 4.4 \mathrm{E}-8 \\ 2001-400 & 4.8 \mathrm{E}-8 & 2.6 \mathrm{E}-7 & 1.6 \mathrm{E}-8 & 1.3 \mathrm{E}-8 \\ 400-600 & 1.9 \mathrm{E}-8 & 1.0 \mathrm{E}-7 & 6.1 \mathrm{E}-9 & 5.1 \mathrm{E}-9 \\ 600-900 & 8.6 \mathrm{E}-9 & 4.7 \mathrm{E}-8 & 2.8 \mathrm{E}-9 & 2.4 \mathrm{E}-9 \\ 900(0)-1100 & 4.8 \mathrm{E}-9 & 2.6 \mathrm{E}-8 & 1.6 \mathrm{E}-9 & 1.3 \mathrm{E}-9\end{array}$

10.0 Fire Department/Brigade Response

The DOE has a formal Interdepartmental Support Agreement with Kirtland Air Force Base (KAFB) to furnish fire protection service to all of SNL's facilities. Such services are required to include: responding to all fire alarm calls, performing periodic familiarization tours of all buildings and preparing and keeping current fire plans and run cards for appropriate buildings and making inspections and flow lests of fire protecion systems as required by NFPA Standards.

Kirtland Air Force Base maintaine a well trained, professionally staffed fire department. All fire detection monitors in the CNSAC facility will be connected directly to the fire department facility. Upon fire detection, it is estimated that the fire department will arrive at the scene within 10 minutes.

The DOE Albuquerque Operations Office furnishes the Kirtland AFB fire department with recommended fire fighting procedures on $\mathrm{KAFB}$ facilities which are considered hazardous or warrant special fire fighting techniques. In the event the CNSAC facility is involved in a fire, the DOE Albuquerque Operations Office shall furnish technical consultants when certain hazardous materials are present. 


\subsection{Recovery Potential}

Recovery from the most likely fire (such as an electronic appliance fire, a waste paper fire in a trash container or an office machine fire) is likely within approximately one week. Sone lost time would be caused by the evacuation of employees, investigation of area/cause and some level of concern/excitement by the employees. However, restoration of any affected fire safety system (e.g., alarms, detectors, sprinkler heads) would be prompt and any cosmetic cleanup would be facilitated because most of the walls are masonry with enamel paint. Sprinkler operation would be unlikely since a reasunable projection of trained employee reaction would be the use of available fire extinguishers.

The occurrence of the maximum credible fire loss would result in damage to the basement area, but no potential for radioactive contamination. Cleanup time would be $4 \cdot 10$ days due to the actuation of the automatic sprinkler system.

Recovery potential will depend of the exact processes taking place in the CNSAC facility. The 1st thru Ith floors will consist of mostly office space and probably at least one computer room. The largest potential for long term loss would be from the destruction of important information stored on the computers. Therefore, it is recommended that all important information stored on the computers be backed up at regular intervals and stored in another facility.

The hasement of the CNSAC tacility has a much larger potential for loss and recovery. This is due to the specialized equipment and experiments taking place in this area. If a fire were to destroy part or all of the bisement, the recovery time would depend on the exact nature of the experiments, whether they could be moved to another location, and on the amount of time it takes to replace damaged equipment.

\subsection{Potential for Toxic, Biological, and/or Radioactive Releases from a Fire}

A fire in the CNSAC facility is likely to produce toxic by-products. Common office machines such as photocopiers have produced toxic pyrolysis products. The combustion or partial combustion of plastic materials used in electrical wiring and in packing materials can produce toxic smoke.

There will not be any storage or use of materials which may pose a biological threat. Therefore, there is no potential for a biological release. 
A variety of relatively low level radionctive sources are mantained in the builing for terting and calibration of detectors. All of these sources have very small amounts of moliontive matertal A* such, they are exempted from special packaging and bibeling reguirements for shipment When met in

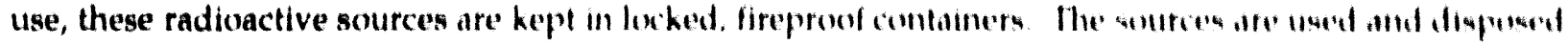

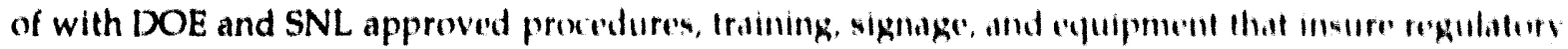
compliance.

In addition to the sealed sources, pieces of thorium, Uranium, Nephturfum, and I'lufronum will occasionally be brought into the facility temporarily for special experiments. Mowt of these preces would be expected to have a mass of less than 10 grams with the exception of Iwo piecies of I/anium allat

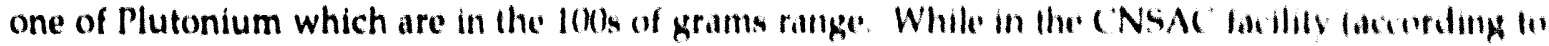

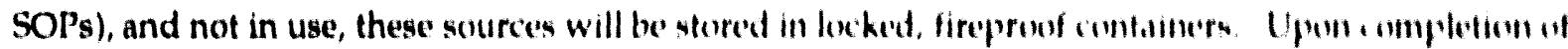

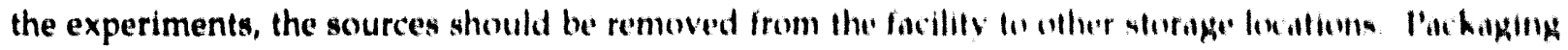
and transportation will be in accordance with Federal, State and lecal cegulations

A radioactive material release is possible and is considered in the moximum powstble fire lows (sention

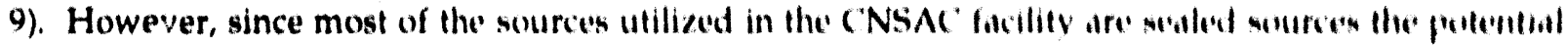
for radioactive material release from a fire is groatly reduced.

\subsection{Emergency Planning}

Emergency Operating Procedures have not been developed for C NSAC hallily, hut will be completed

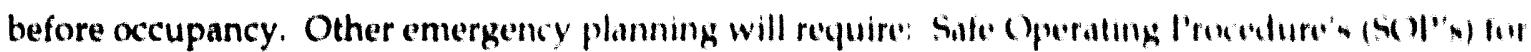

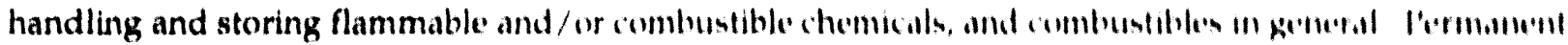

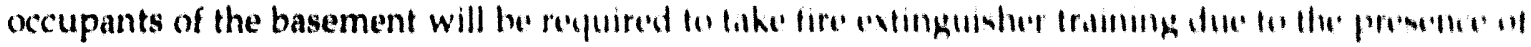

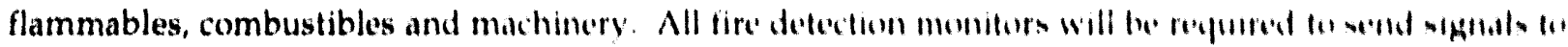

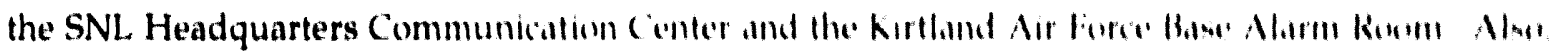

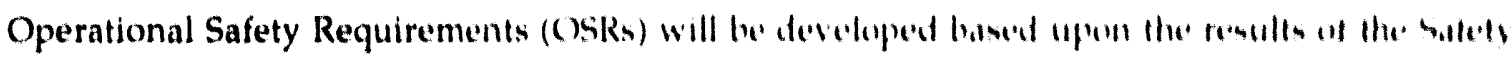

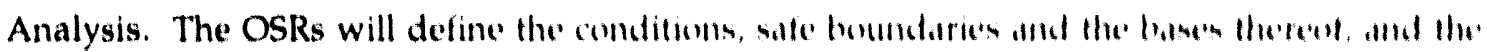

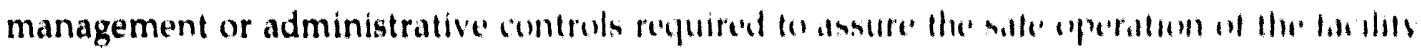


From a security standpoint, the Department of Energy Albuquerque Office (DOE/AL) and/or DOE/AL contractor guard forces shall be in charge of entry into secured areas. Kirtland AFB guard forces shall be in charge of entry into Kirtland AFB areas under such emergencies. DOE/AL shall handle press reluases for fires occurring within DOE/AL areas.

Fire safety measures ivill not affect the security of the facility. However, in the event of a fire or the acturtion of fire alarms, the CNSAC facility would need to be evacuated and access provided to qualified fire protection and emergency response personnel.

The SCIF portion of each floor will have one opening into the non-SCIF portion and one cxit leading directly to a building exit. These doors will be equipped with emergency opening devices to allow egress to persons inside the SCIF during an emergency. In addition, the main entrance door to the SCIF will be open during normal operating hours and will not be closed and locked while anyone is in the SCIF area.

The CNSAC facility is designed to the facility use category of important or low hazard facility per UCRL. 15910 Natural Phenom: na Guidelines. The design basis natural phenomena events are based on the Sandia site specific information and the usage category of the facility. Natural hazards are not anticipated to affect the operability of the fire protection systems, but could impair the ability of the emergency response personnel to respond to a fire alarm and/or a fire. Therefore this facility would withstand the design basis earthquake and the design basis wind. External flooding is considered highly unlikely, due to the arid climate and the long distance to the nearest river or arroyo. However, the facility is being designed to the maximum credible flood as required by UCRL-15910 [Ref. 12].

\subsection{Exposure Fire Potential}

There are several buildings in the vicinity of the CNSAC facility which could pose an exposure fire potentral. However, it is expected that with automatic fire suppression available in these buildings In combination with the response of the fire brigade the exposure fire potential is minimal.

Additionally, the threat from transportation fires was considered minimal due to the response of the 
fire brigade and the magnitude and proximity of the fire required to present an exposure fire potential.

The environment does not support severe growth of trees and bushes in the vicinity of the CNSAC facility. Additionally, there will be an overlay of concrete, stones and gravel to prevent the growth of underbrush.

\subsection{References}

1. Architectural/Structural/Civil Design Analysis, CNSAC Facility, Sandia National Laboratories, Design Professionals Incorporated, Title II Submittal, February, 24, 1992.

2. Safety Assessment for the Center for National Security and Arms Control (CNSAC), SAND922170.

3. Guidance on the Performance of Fire Hazards Analysis, US DOE Memorandum EH-31.3, November 7, 1991.

4. "FIRAC Users Manual: A Computer Code to Simulate Fire Accidents in Nuclear Facilities", B.D. Nichols and W.S. Gregory, Los Alamos National Laboratory

5. A Guide to Good Practices at Plutonium Facilities, PNL-2086, Rev. 1, July, 1987.

6. J. E. Ayer, et. al., Nuclear Fuel Cycle Facility Accident Analysis Handbook, NUREG 1320, U.S. NRC, May 1988.

7. J. Mishima, Recommended Values and Technical Bases for Airborne Release Fractions (ARFs), Airborne Release Rates (ARRs), and Respirable Fractions (RFs) - Draft Rev. 1 Defense Programs Nuclear Facility Safety Survey, U.S. DOE, July 1992.

8. J. Mishma, Plutonium Re!ease Studies II. Release from Ignited, Bulk Metallic Pieces, BNWL-B257, Pacific Northwest Laboratory, Richland, WA, November, 1966. 
9. MACCS - MELCOR Accident Consequence Code System, D.I. Char 'n et. al., NUREG/CR-4691, February 1990.

10. Annals of the ICRP, Publication 30, Limits for Intakes of Radionuclides by Workers, Pergamon Press, Elmsford, NY, 1980.

11. External Dose Rate Conversion Factors for Calculation of Dose to the Public, DOE/EH-0070, US DOE, July 1988.

12. R.P. Kennedy, et. al., Design and Evaluation Guidelines for Department of Energy Facilities Subjected to Natural Phenomena Hazards, UCRL-15910, LLNL, Livermore , CA, May, 1989. 
APPENDIX A

FIRAC INPUT \& OUTPUT

$\Lambda .1$ 


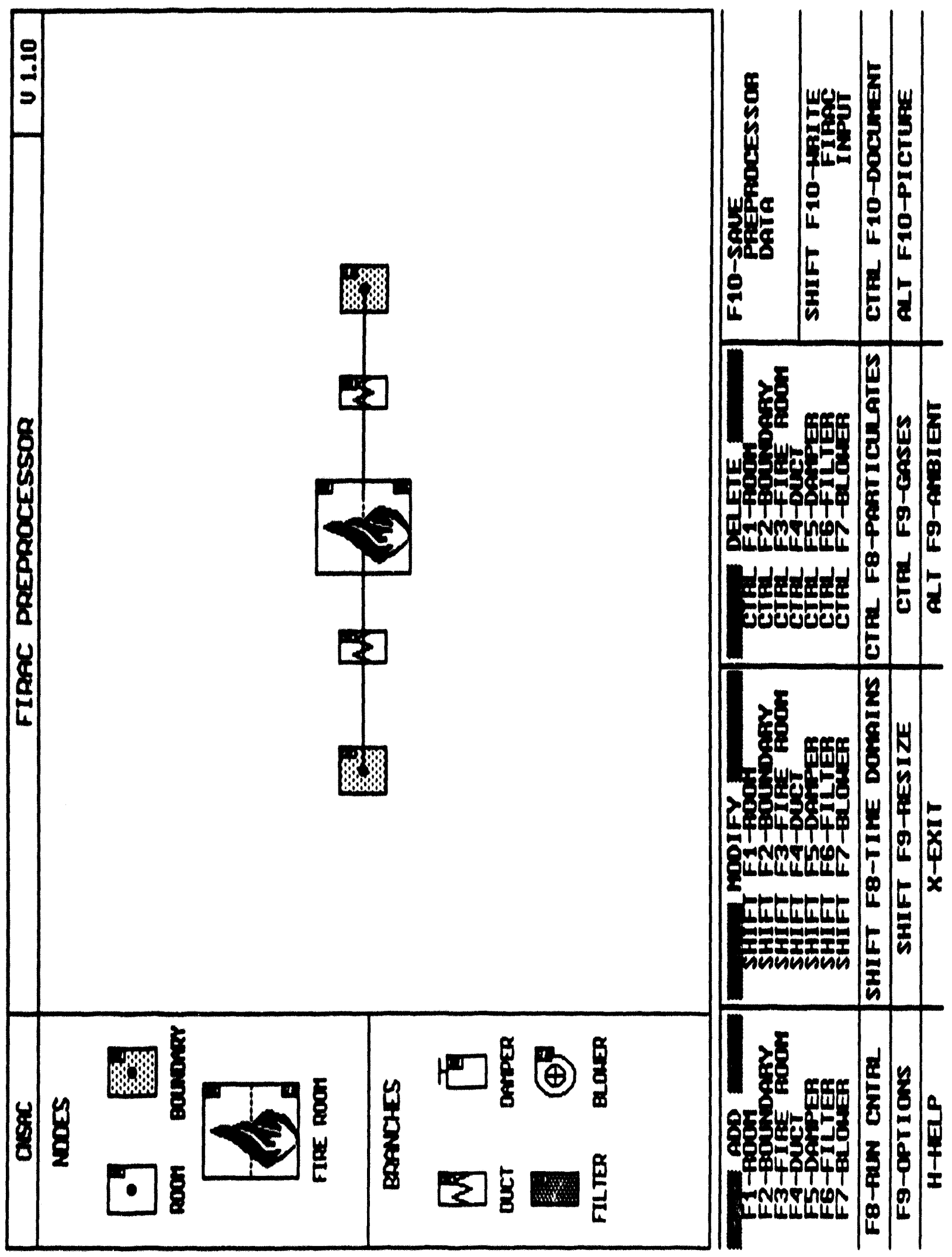



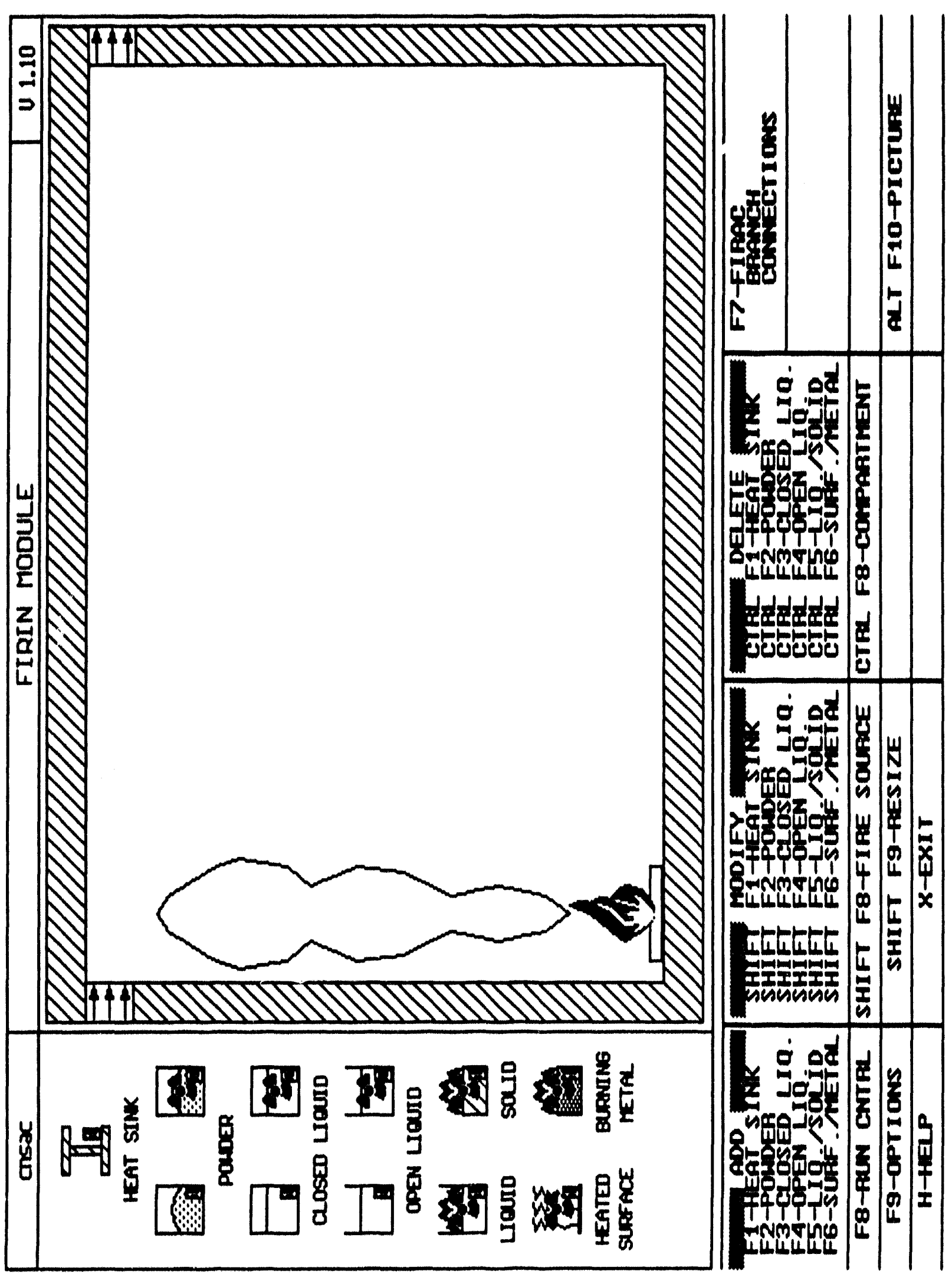
Fire Compartment Thermal Effects

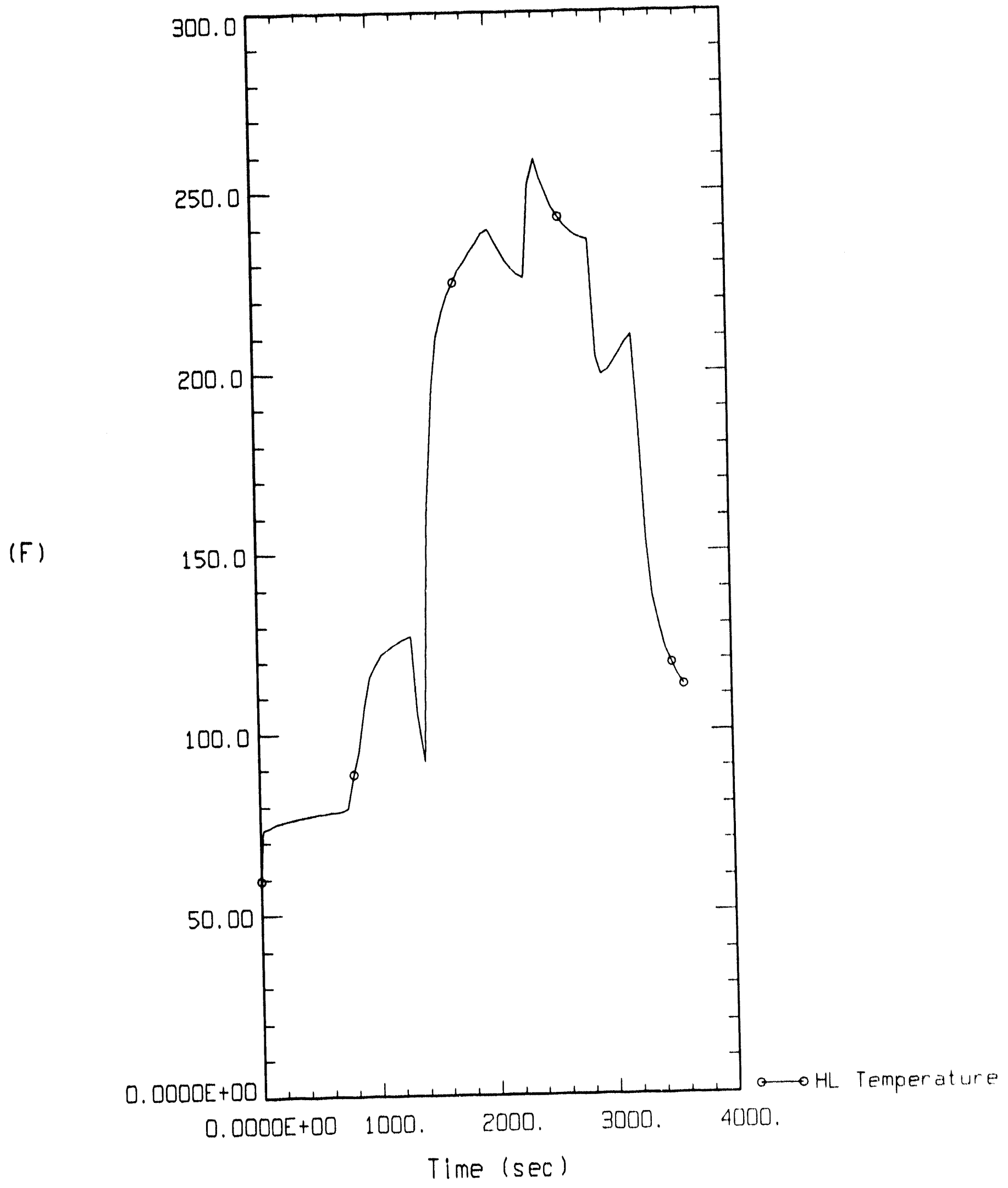


Fire Compartment Thermal Effects

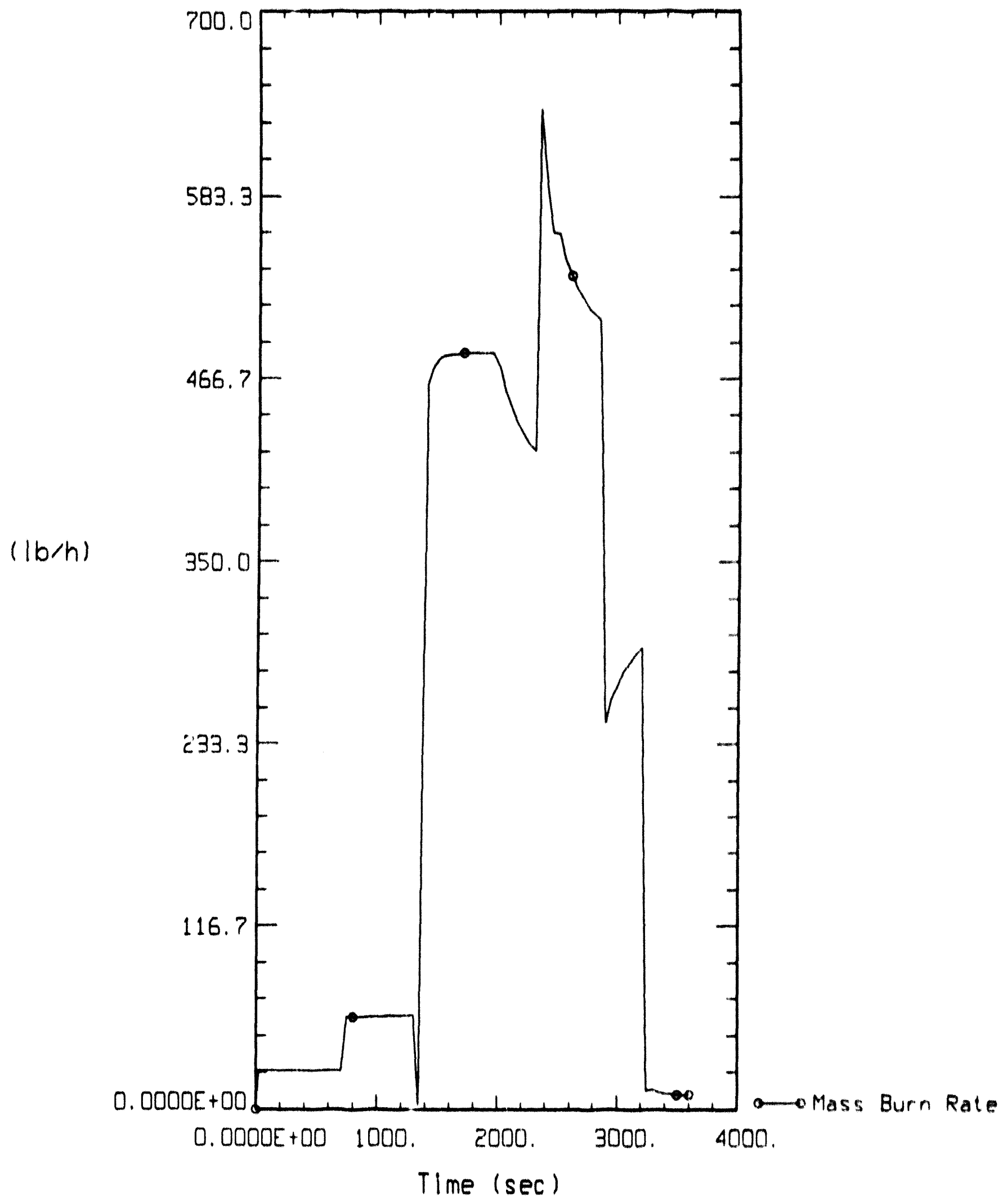




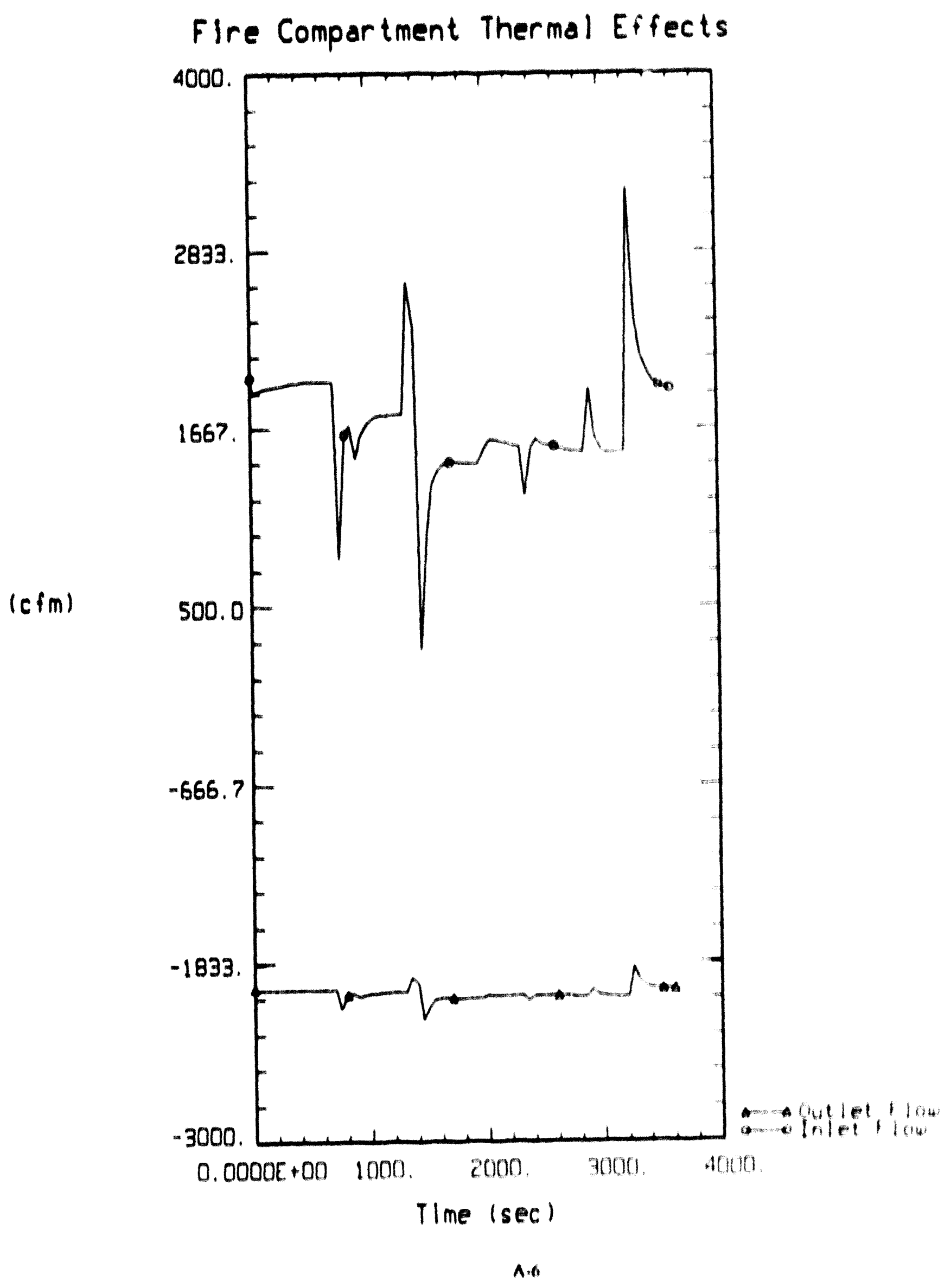




\section{Smoke Source Term Effects}

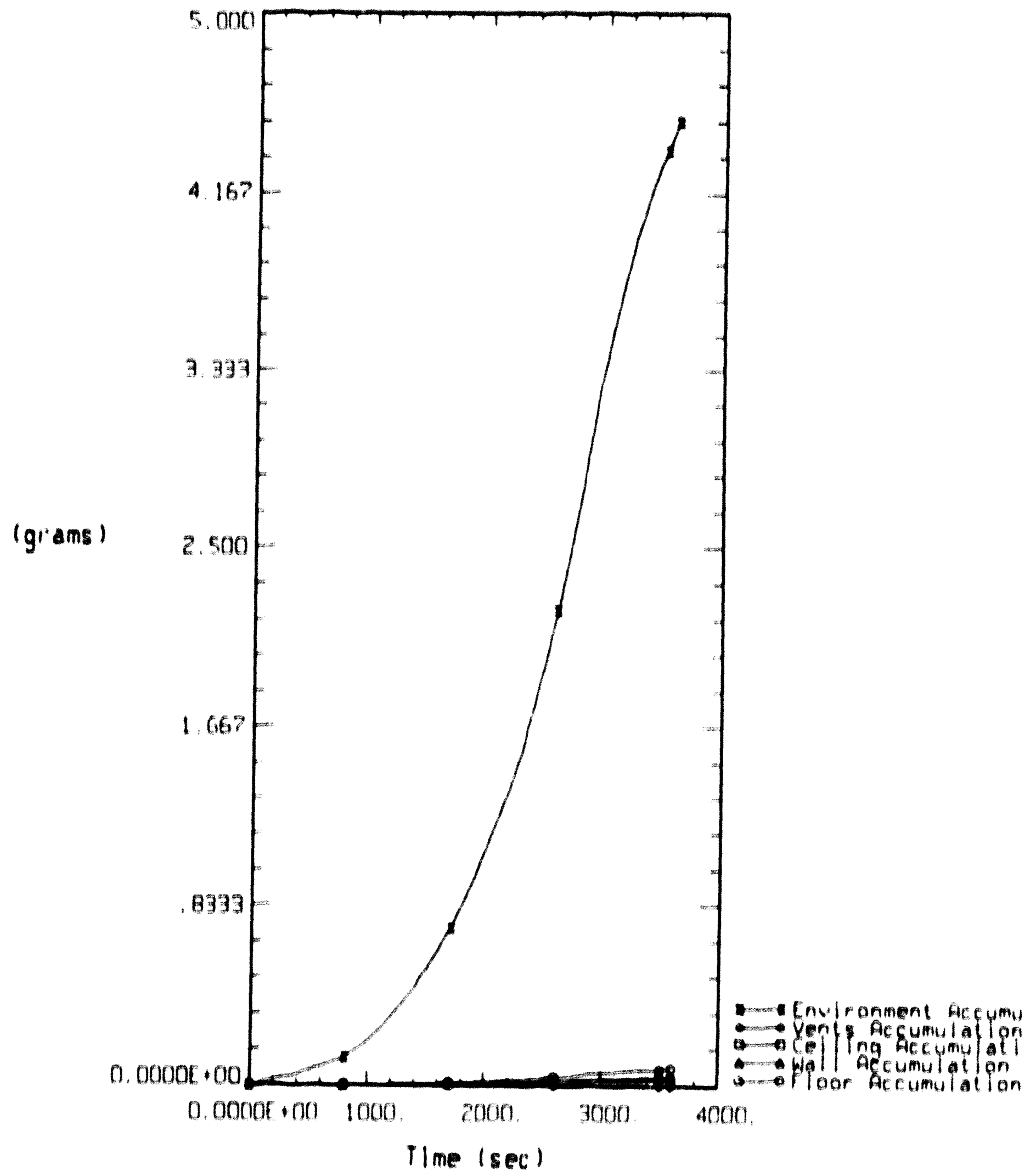


PAOE 1 PIRAC DOCUMENTATION FILEI CNSAC.dOC

FP VERSION 1.10

FILI CNSAC.dOO

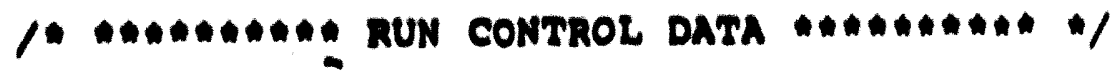

Run control optioni $8 T$

In1tial Output Time (a): 0.0

Tlime between outputs (a)i 0.5

wat output TIme (0) 3600.0

No. speolal output rimes (a), 0

Pirot:

second I

rinird:

Pourthi

Fiethi

Max. Itarationsi

Convergence Criterioni

Particle Dopositioni

Particle Eneralnment:

Inltial proseure Inputi

Inlelal Temperature Inputs

Buoyanoy Tarmi

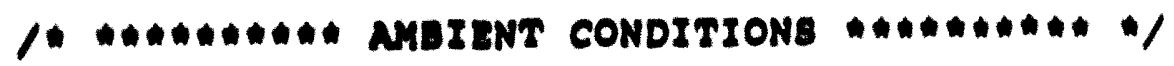

Pressure (pola)! 14.696

Temperature (r), 60.0

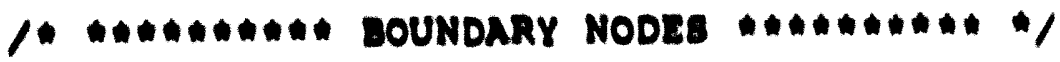

Number of Boundary Nodes! 4

Dosorlptioni INLET BOUNDARY

Node Number! 1

Node Typer 0

Inlelal Prosaure $(\ln w . g$.$) ) 0.0$

Proseure runction I.D.:

Initelal ramperature (F): 60.0

Tomperature Punotion I.D.I

Elevation $(f t): 0.0$

Dosordptioni TIRE INLET

Node Number: 2

Node Typel 1

Indedal Pressure (In w.q.) 0.0

Preseure Punotion I.0.1 0

Indelal Temporature (F): 60.0

Temperature runot Ion I.D.I 0

Elovation (et): 0.0 
PAGE 2 TIRAC DOCUMENTATION FILE: CNSAC.dOC

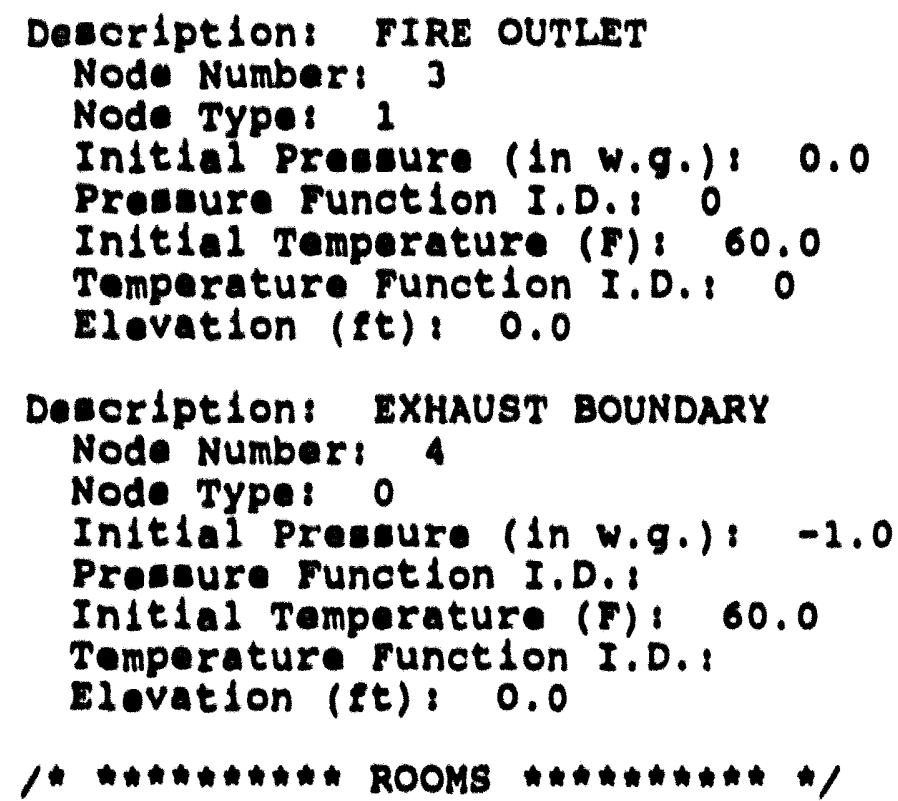

Number of Rooms: 0

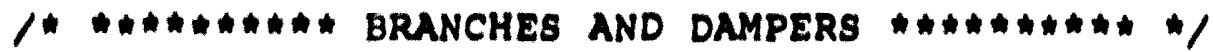

Number of Branchas: 2

Number of Control Dampers: 0

Description: INLET DUCT

Branch Number: 1

Upetream Node Number: 1

Downetream Node Number: 3

Intelal Flow (cfm): 2000.0

Flow Area (et2): 3.14

Duct Length ( $f t$ ): 10.0

Componant Type:

Pressure Differential (In w.g.): 0.0

Blower Curve I.D.:

Forward Resistance Coefflelent: 1.60534

Reverse Resistance Coefflelent: 1.60534

Filter Type:

Duct Helght (et):

Floor Area (ft):

Heat Transfer Option: 0

Roughness Helght (m):

Bend Angle (rad):

Band Radiue (m):

Drag coefflcient Factor:

Bhape Ind Icator:

Description: EXHAUST DUCT

Branch Number: 2 
PAGE 3 FIRAC DOCUMENTATION FILE: CNSAC.dOC

Upetream Node Number: 2

Downetream Node Number: 4

Intelal Flow (ctm): 2000.0

Flow Area (et2): 3.14

Duct Langth $(e t): 10.0$

Component Type: D

Preseure Difeerential (In W.g.): 0.0

Blower Curve I.D.:

Forward Resletance Coefflcient: 1.60534

Revaree Resietance Coefelclent! 1.60534

Filter Typa:

Duot Helght (et):

Floor Area (et)?

Hoat Transer Option: 0

Roughnese Halght (m) :

Bend Angle (rad):

Bond Radlue (m) :

Drag coeficient Factor:

Shape Indicator:

/゙

Number of Filter Typea: 0

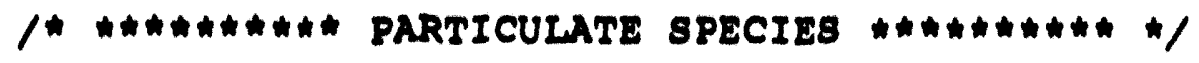

Number of Particulate species: 0

/

Number of Gas spectes: 0

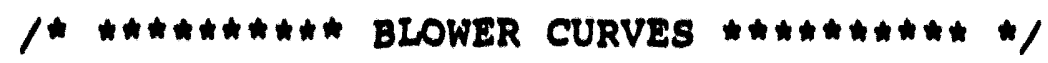

Number of Blower Curves: 0

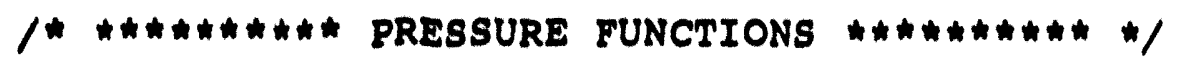

Number of Pressure Functions: 0

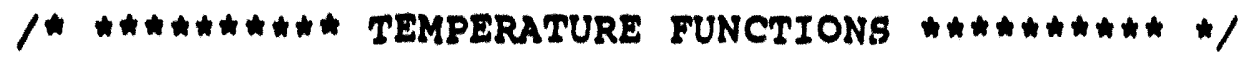

Number of Temperature Functions: 0

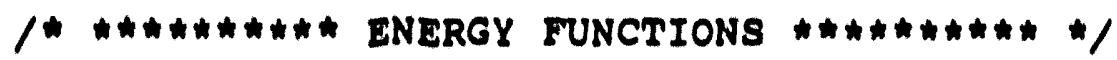

Number of Energy Functions: 0

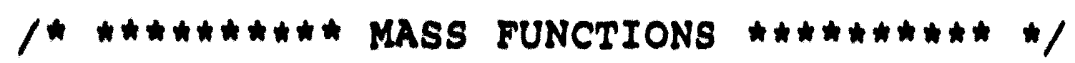

Number of Mass Functions: 0 
PAGE 4 FIRAC DOCUMENTATION FILE: CNSAC.dOC

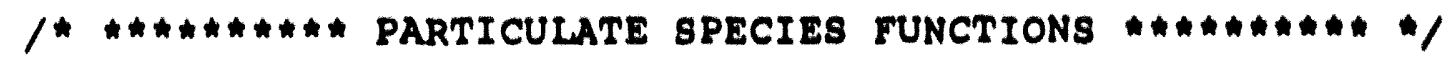
Number of Particulate species Functions: 0

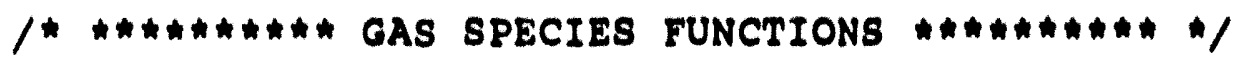
Number of Gas species Functions: 0

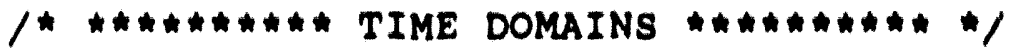

Time Domain: 1

Dtmax (s): 0.5

Tend (s): 100.0

Edint (s): 1.0

Time Domain: 2

$\operatorname{Dtmax}(8): 1.0$

Tend (8): 3600.0

Edint (s): 10.0

/*

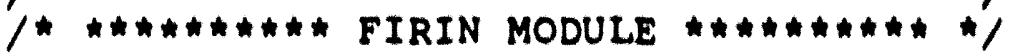

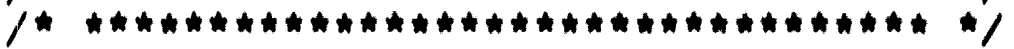

IFIRIN flag: 0

Inlet Node Number: 2

outlet Node Number: 3

Third Node Number 0

Inlet Branch Number: 1

Inlet Branch Dlameter (ft): 2.0

outlet Branch Number: 2

Outlet Branch Diameter (ft): 2.0

Third Branch Number:

Third Branch Diameter ( $f t)$ :

Third Branch Elevation ( $f t)$ :

Third Branch Flow Direction:

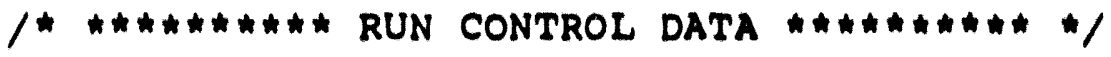

Fire Duration (B): 3600.0

Fire Start Time (s): 0.0

Print Interval (tIme steps): 50

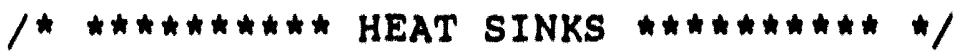

Number of Heat Sinks: 0

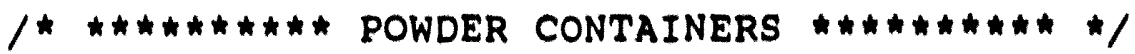


PAGE 5 FIRAC DOCUMENTATION FILE: CNSAC.dOC

Number of Powder Containers: 0

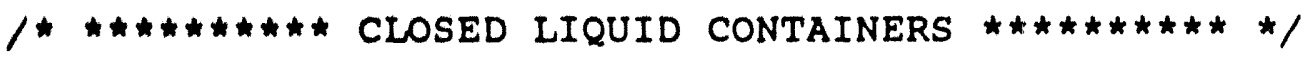

Number of closed Liquid Containers: 0

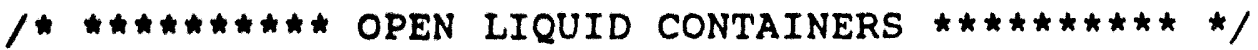

Number of Open Liquid Containers: 0

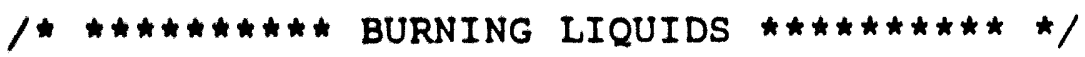

Number of Burning Liquids: 0

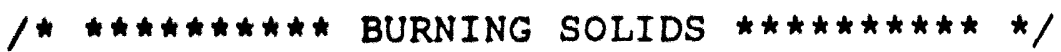

Number of Burning Solids: 0

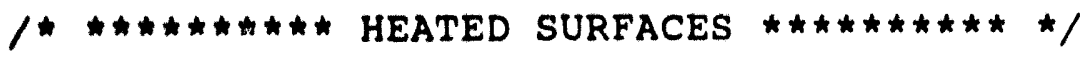

Number of Heated Surfaces: 0

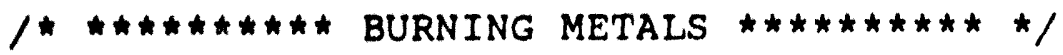

Number of Burning Metals: 0

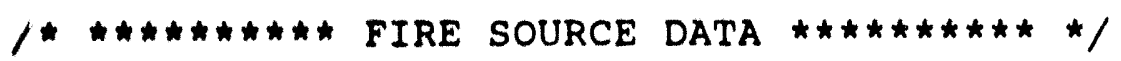

Ignition Energy Flag: 1

$0=$ Burning order

$1=$ Ignition Energy

2-Burning Rate

Maximum Burning Order: 2

Burning order: 1

Combustible 1 Fual Mass ( $1 \mathrm{bm}$ ):

Surface Area (ft2):

Combustible 2 Fuel Mass (lbm):

Surface Area (ft2):

Combustible 3 Fuel Mass (lbm):

Surface Area (ft2):

Combustible 4 Fuel Mass (1bm):

Surface Area (ft2):

combustible 5 Fuel Mass (1bm):

Surface Area (ft2):

Combustible 6 Fuel Mass (lbm): 20.0

Surface Area (ft2): 6.0

Combustible 7 Fuel Mass (1bm): 4.0

Surface Area (ft2): 1.5

Combustible 8 Fuel Mass ( $1 \mathrm{bm}$ ): 
PAGE 6 FIRAC DOCUMENTATION FILE: CNSAC.dOC

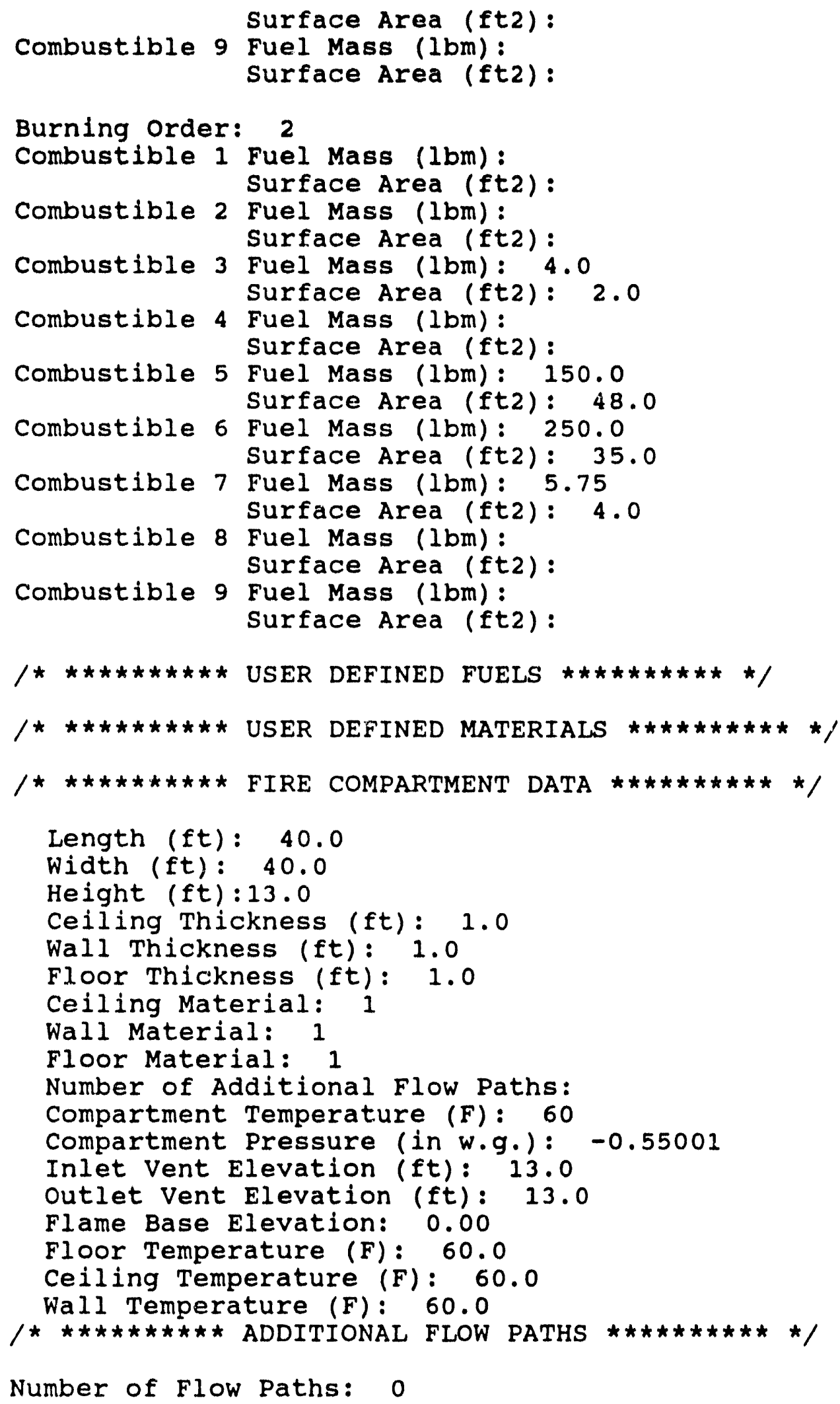




\section{APPENDIX B}

\section{MACCS INPUT \& OUTPUT}




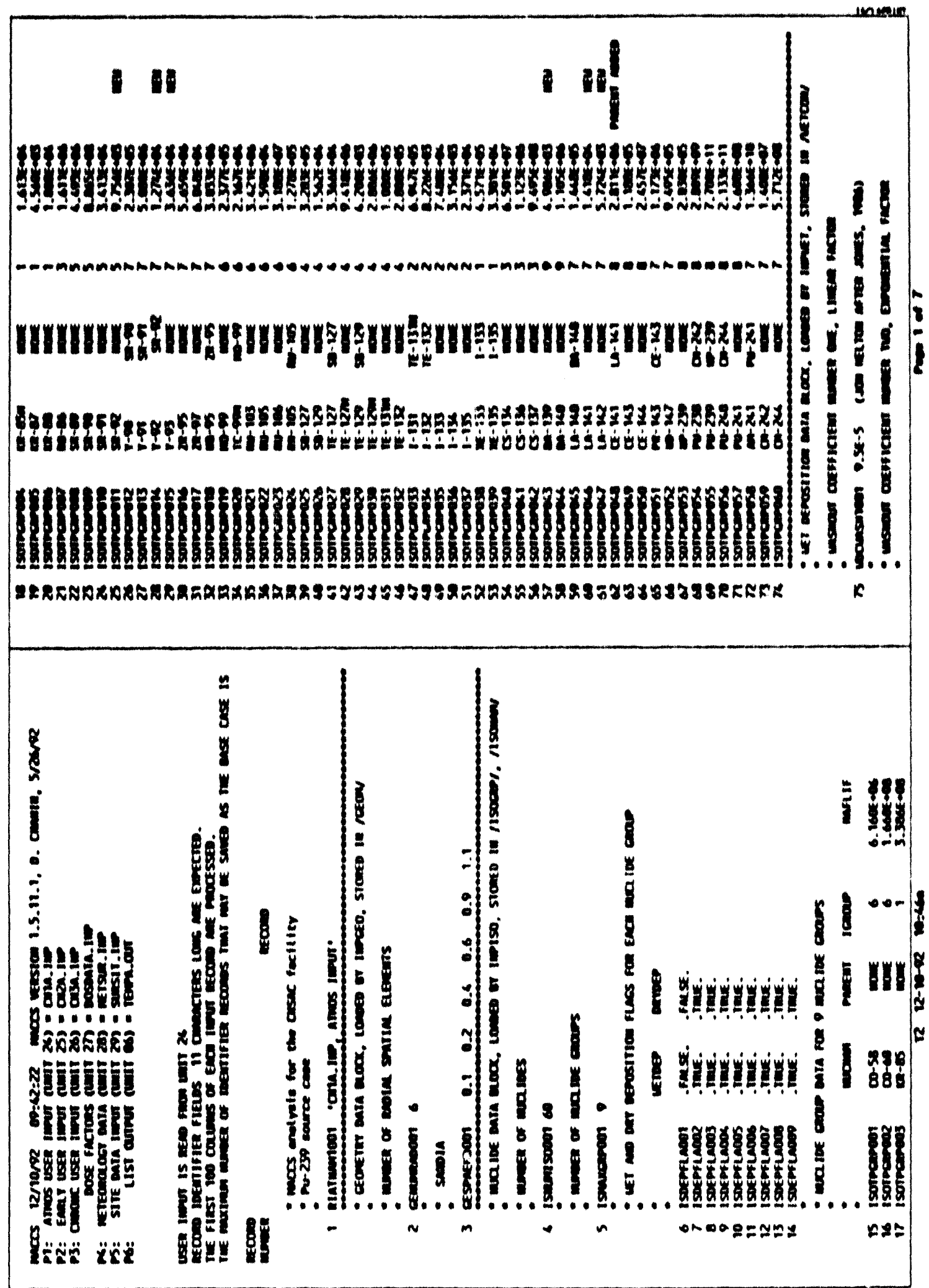




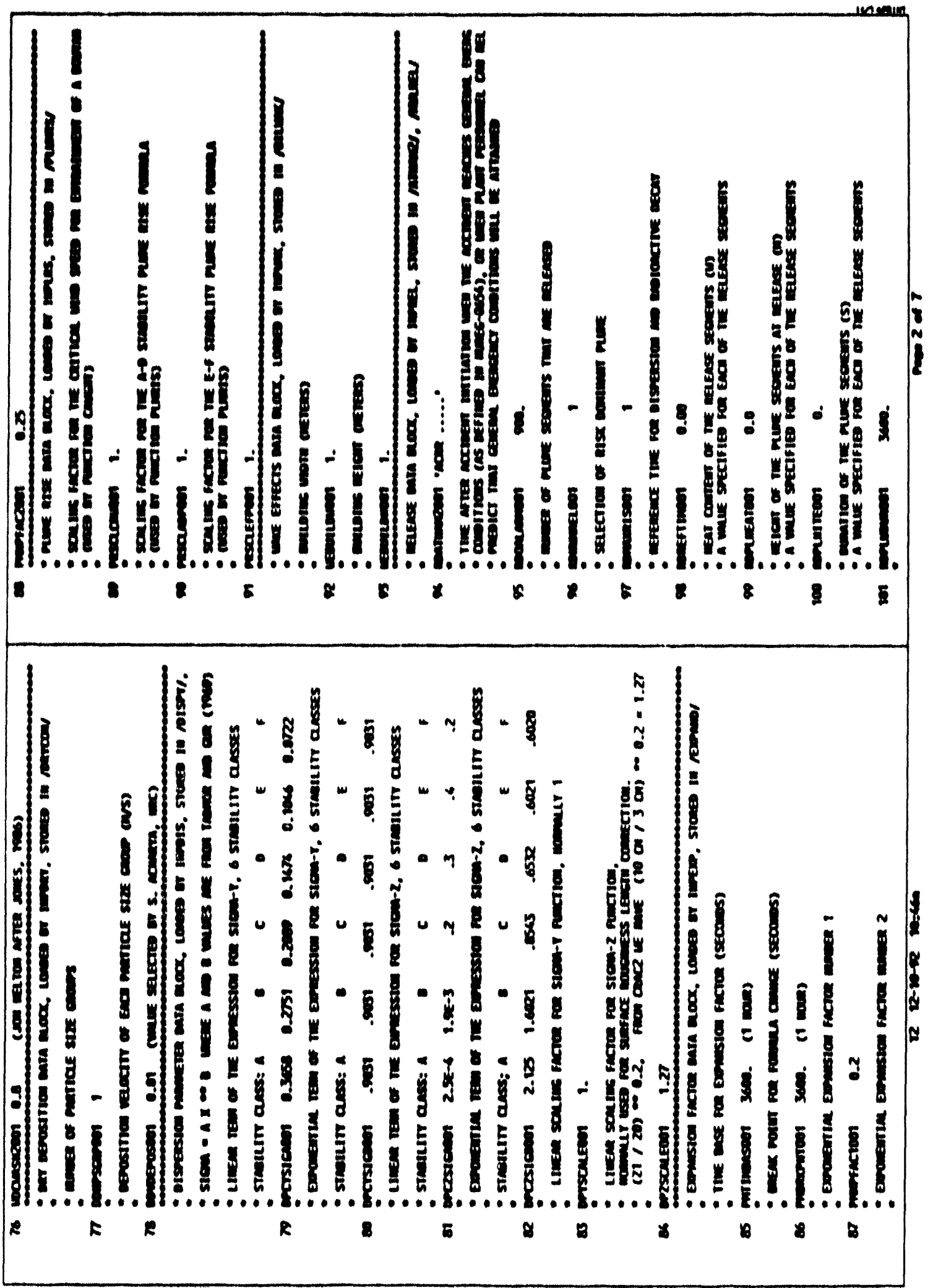




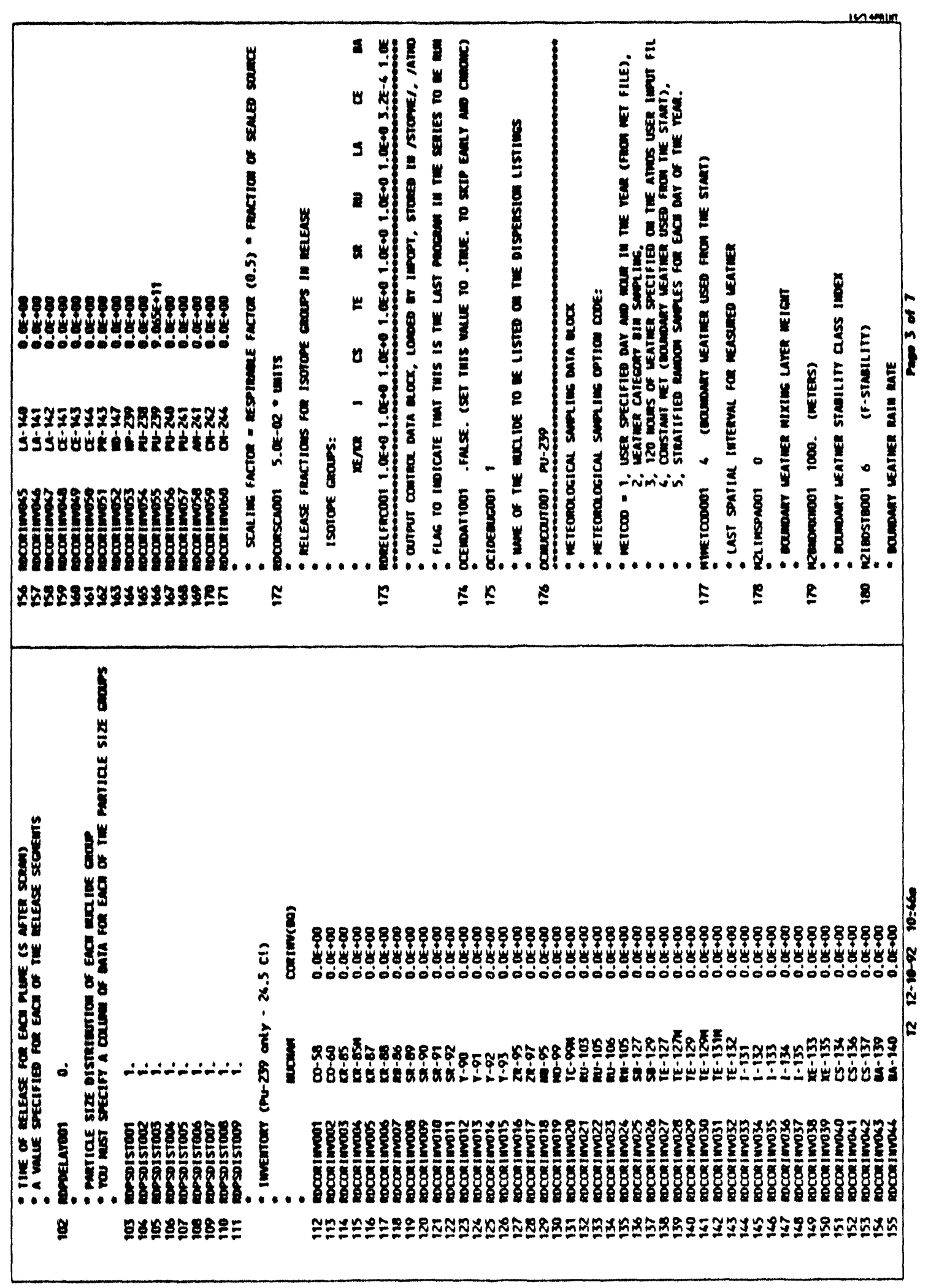




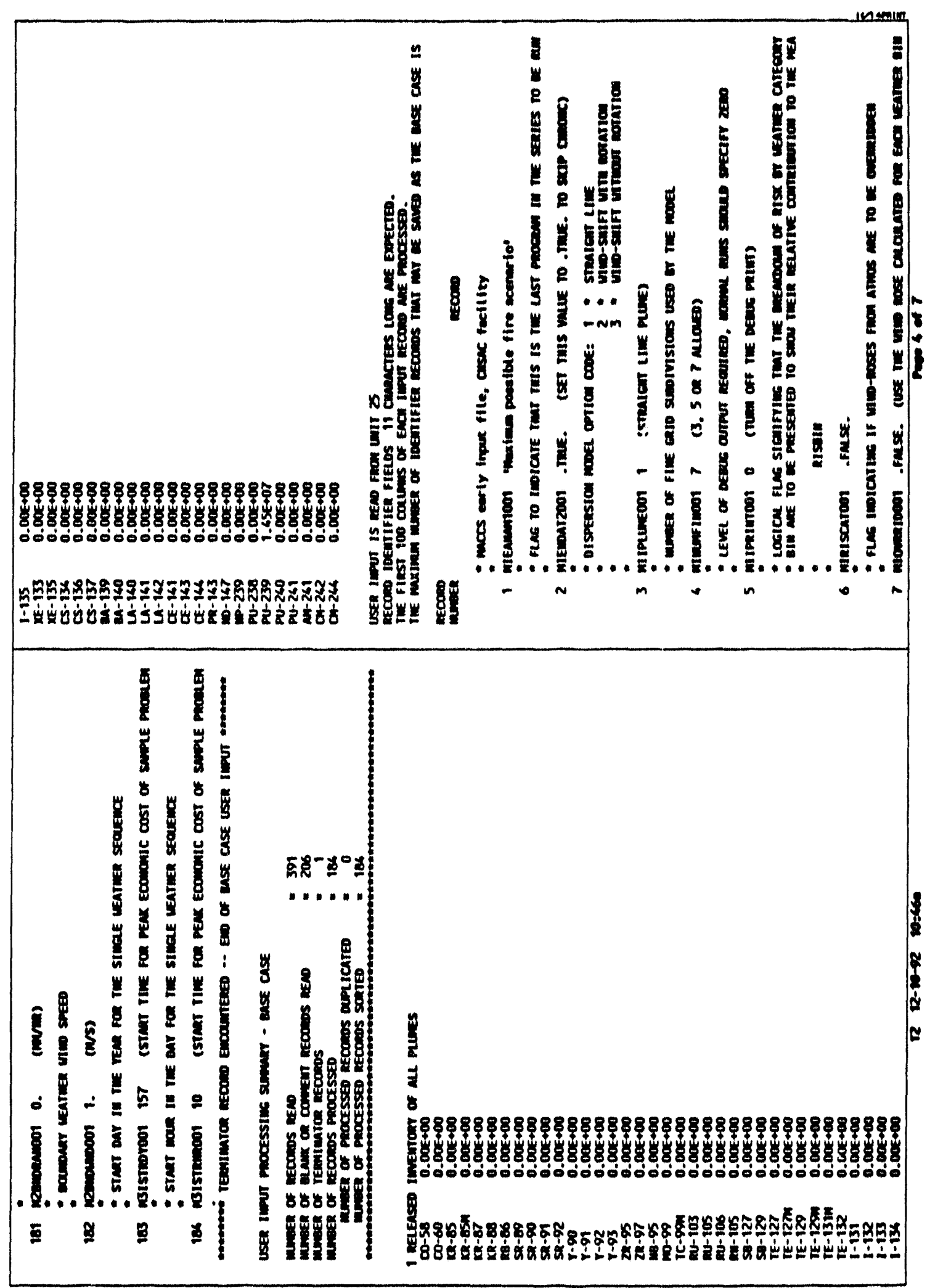




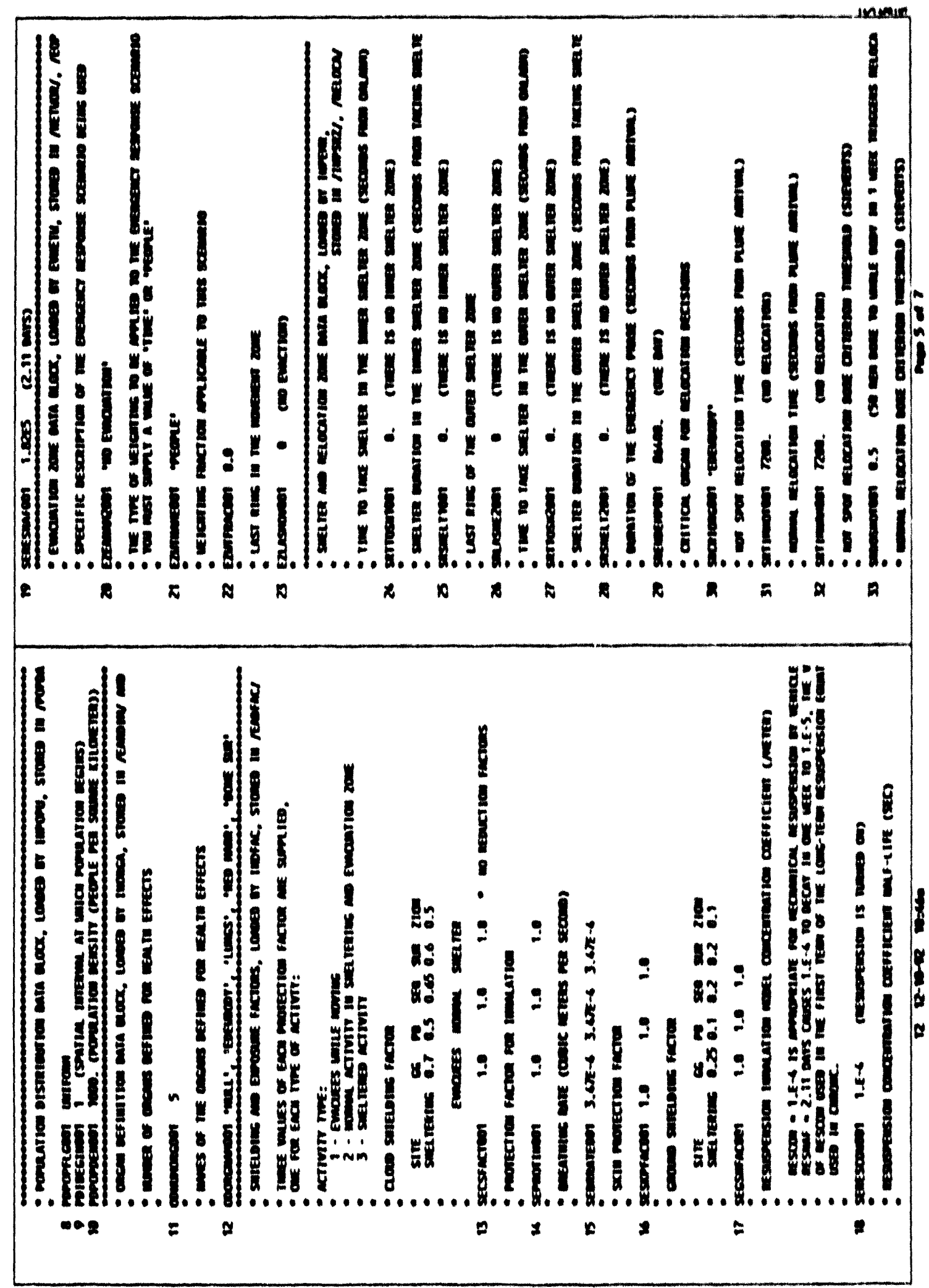




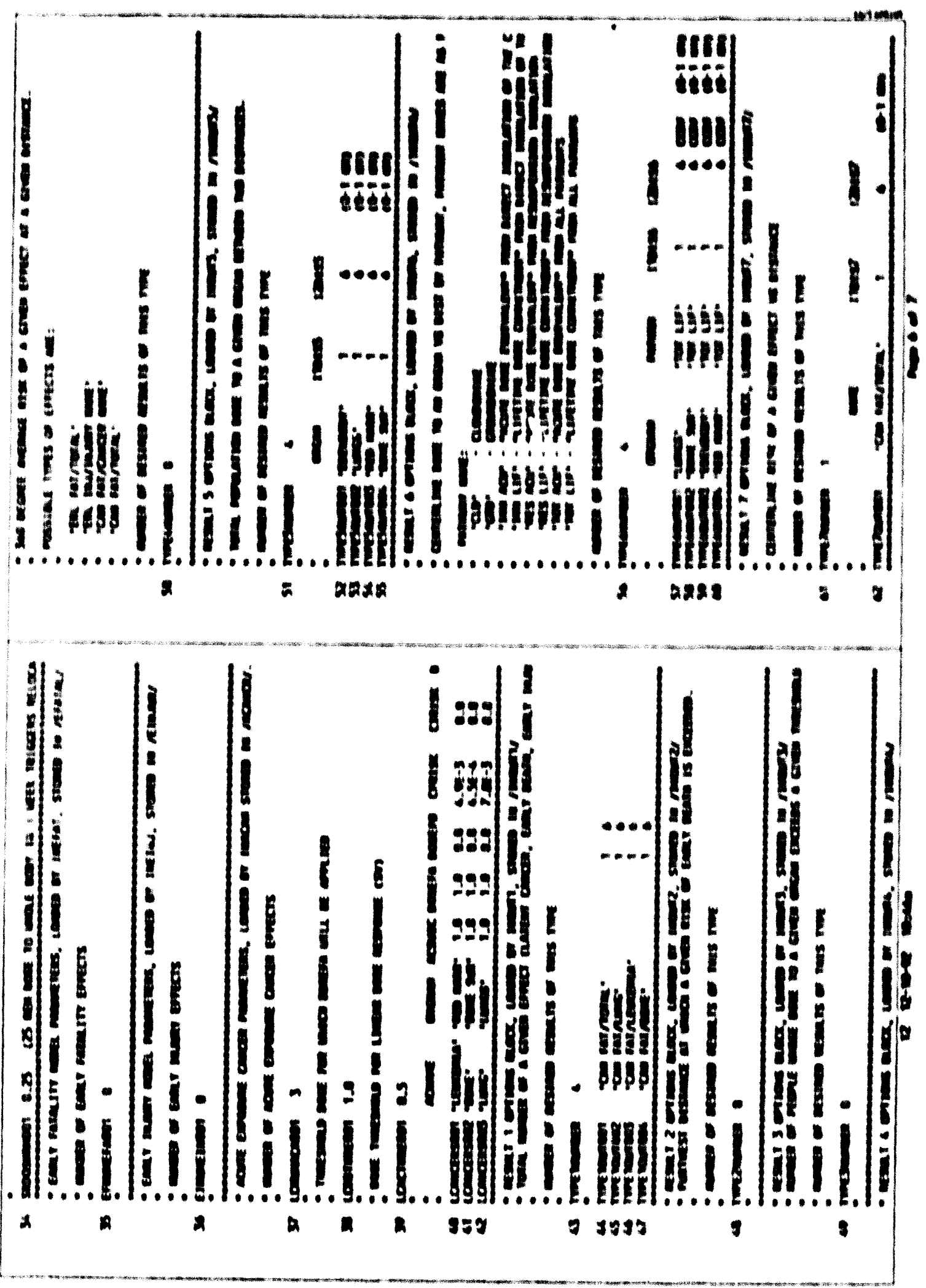





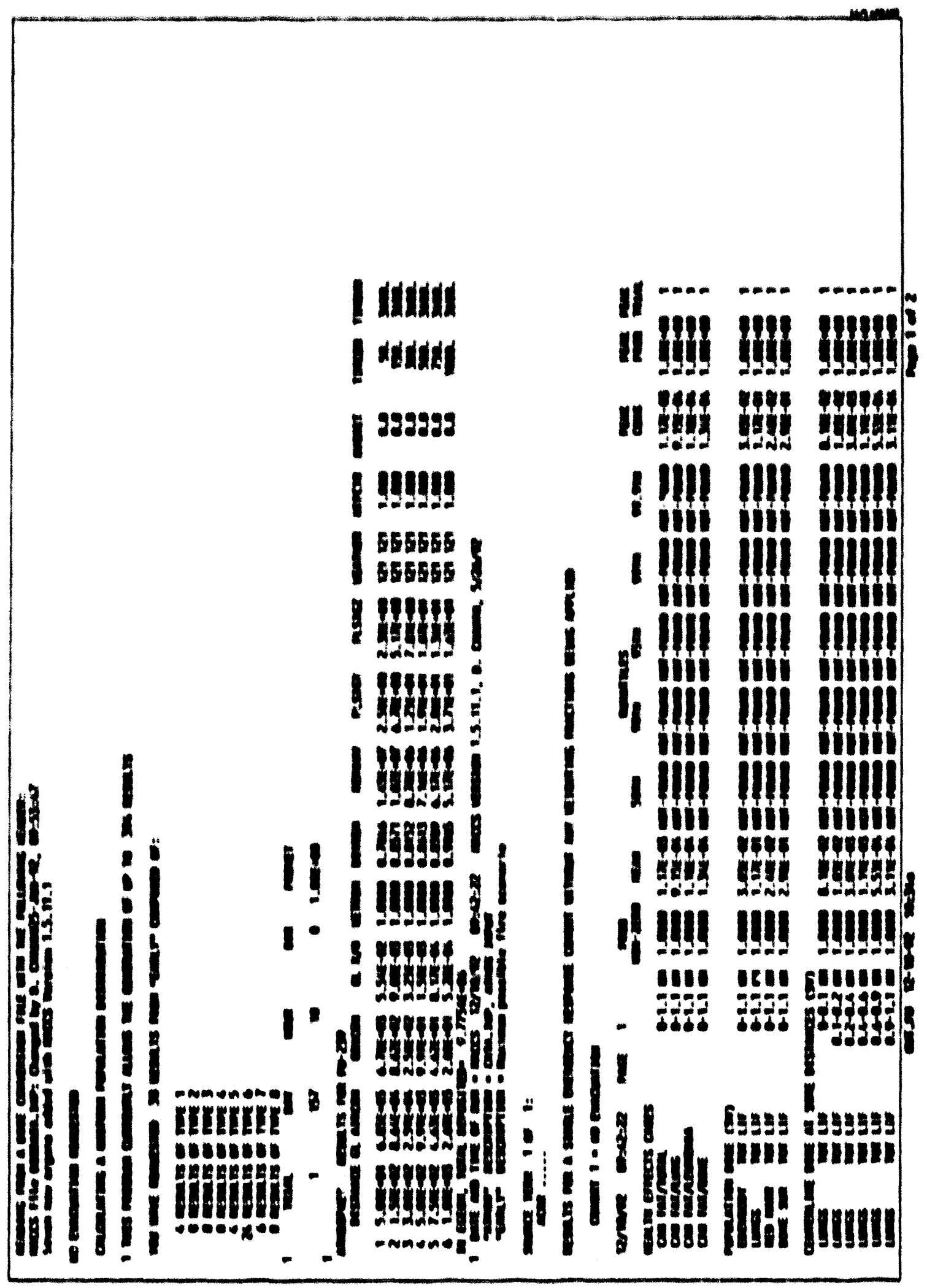




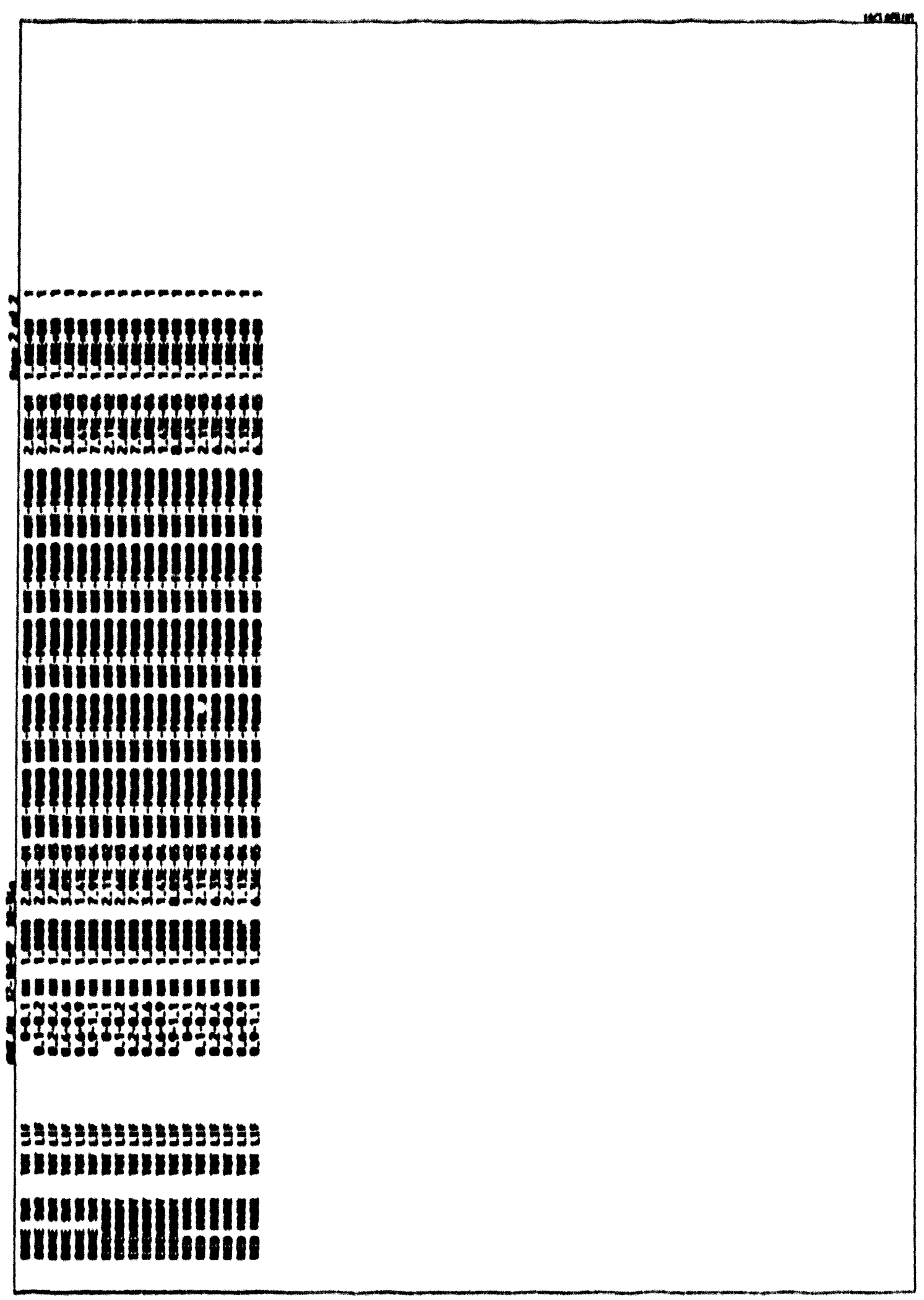









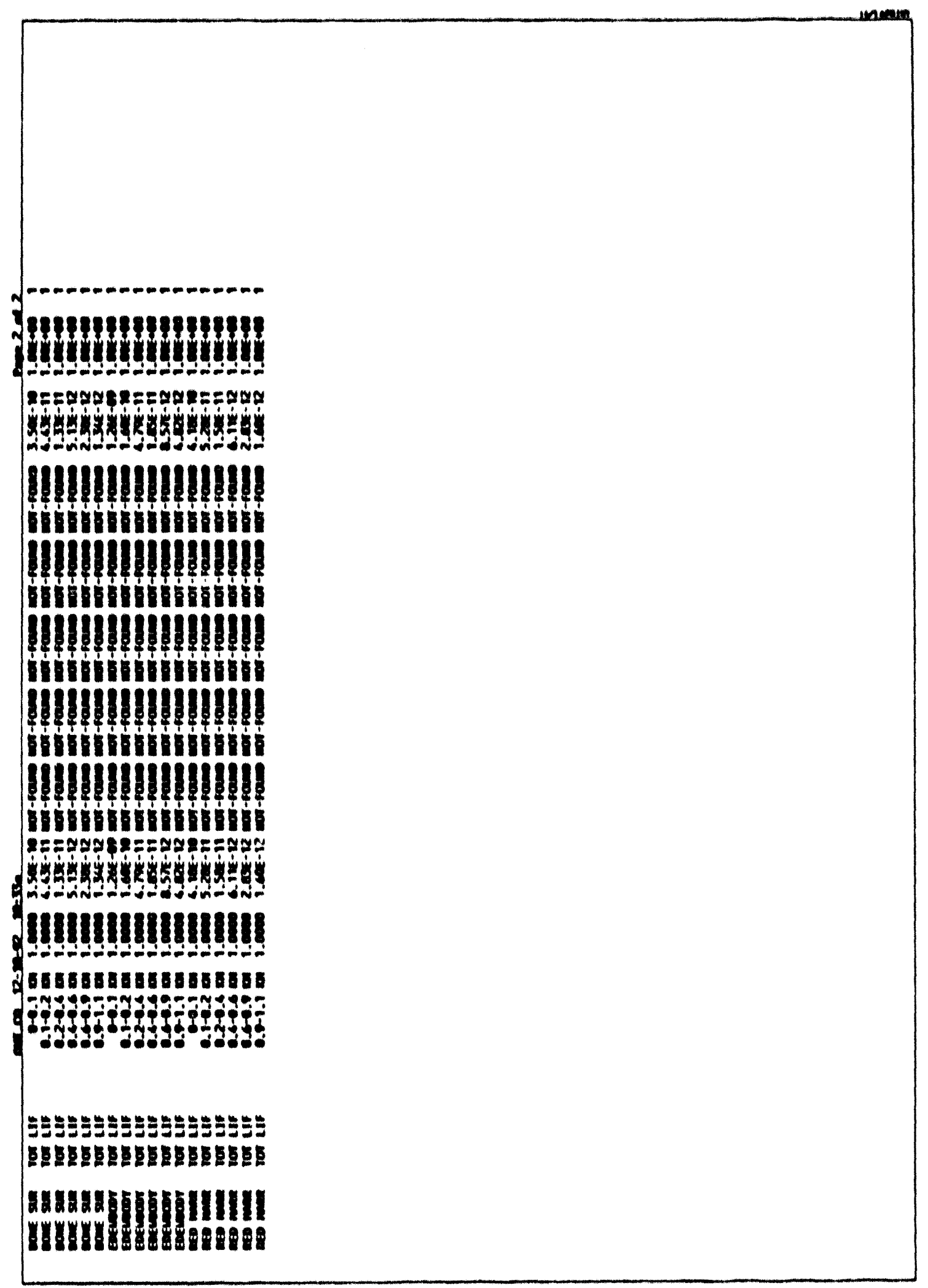




\section{DISTRIBUTION:}

6400 N. R. Ortiz

6449 M. P. Bohn

6449 E. W. Klamerus (3)

6449 J. A. Lambright

6523 L. F. Restrepo

7942 J. C. Dawson (3)

8523.2 Central Technical Files

7141 Technical Library (5)

7191 Technical Publications

7613-2 Document Processing DOE/OSTI (10)

S. B. Ross

Science \& Engineering Associates

6100) Uptown Blyd. NE

Suite 700

Albuquerque, NM 87110

(2 Copies) 

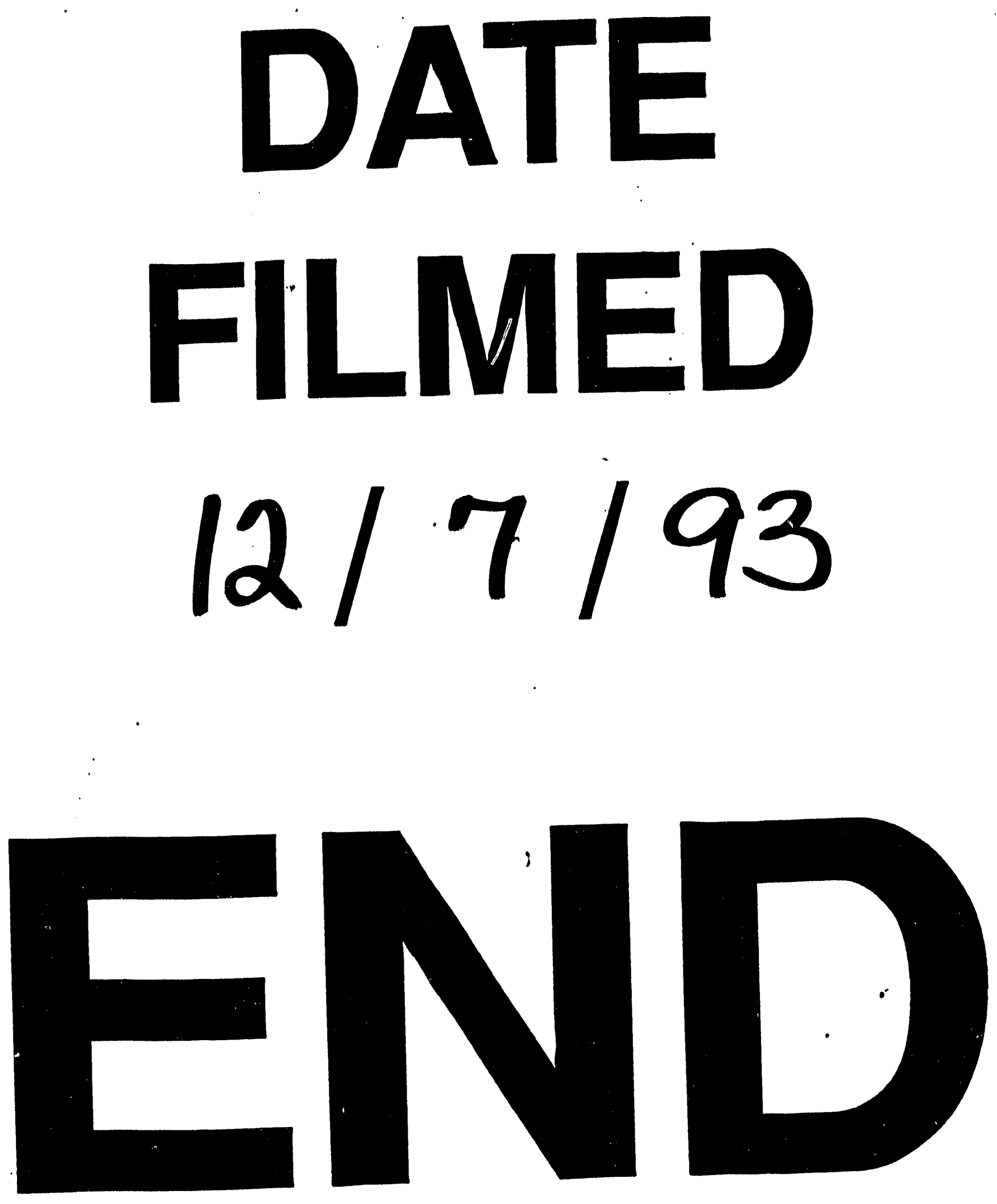


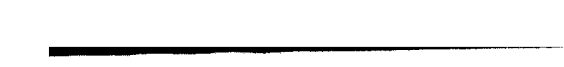

